\title{
Assessing the impacts of $1.5^{\circ} \mathrm{C}$ global warming - simulation protocol of the Inter-Sectoral Impact Model Intercomparison Project (ISIMIP2b)
}

Katja Frieler $^{1}$, Stefan Lange ${ }^{1}$, Franziska Piontek ${ }^{1}$, Christopher P. O. Reyer ${ }^{1}$, Jacob Schewe $^{1}$, Lila Warszawski $^{1}$, Fang Zhao ${ }^{1}$, Louise Chini ${ }^{2}$, Sebastien Denvil ${ }^{3}$, Kerry Emanuel ${ }^{4}$, Tobias Geiger ${ }^{1}$, Kate Halladay ${ }^{5}$, George Hurtt ${ }^{2}$, Matthias Mengel $^{1}$, Daisuke Murakami ${ }^{6}$, Sebastian Ostberg ${ }^{1,7}$, Alexander Popp ${ }^{1}$, Riccardo Riva ${ }^{8,9}$, Miodrag Stevanovic ${ }^{1}$, Tatsuo Suzuki ${ }^{10}$, Jan Volkholz ${ }^{1}$, Eleanor Burke ${ }^{5}$, Philippe Ciais ${ }^{11}$, Kristie Ebi ${ }^{12}$, Tyler D. Eddy ${ }^{13,14}$, Joshua Elliott ${ }^{15,16}$, Eric Galbraith ${ }^{17,18}$, Simon N. Gosling ${ }^{19}$, Fred Hattermann ${ }^{1}$, Thomas Hickler $^{20}$, Jochen Hinkel $^{21,22}$, Christian Hof $^{20}$, Veronika Huber ${ }^{1}$, Jonas Jägermeyr ${ }^{1}$, Valentina Krysanova ${ }^{1}$, Rafael Marcée ${ }^{23}$, Hannes Müller Schmied ${ }^{20,24}$, Ioanna Mouratiadou ${ }^{1,25}$, Don Pierson ${ }^{26}$, Derek P. Tittensor ${ }^{13,27}$, Robert Vautard ${ }^{11}$, Michelle van Vliet $^{28}$, Matthias F. Biber ${ }^{20}$, Richard A. Betts ${ }^{5,29}$, Benjamin Leon Bodirsky ${ }^{1}$, Delphine Deryng ${ }^{15,30}$, Steve Frolking ${ }^{31}$, Chris D. Jones ${ }^{5}$, Heike K. Lotze ${ }^{13}$, Hermann Lotze-Campen ${ }^{1,32}$, Ritvik Sahajpal ${ }^{2}$, Kirsten Thonicke $^{1}$, Hanqin Tian ${ }^{33,34}$, and Yoshiki Yamagata ${ }^{35}$

${ }^{1}$ Potsdam Institute for Climate Impact Research, 14473 Potsdam, Germany

${ }^{2}$ Department of Geographical Sciences, University of Maryland, College Park, MD, USA

${ }^{3}$ Institut Pierre-Simon Laplace, Paris, France

${ }^{4}$ Program for Atmospheres, Oceans and Climate, Massachusetts Institute of Technology, Cambridge, Massachusetts, USA

${ }^{5}$ Met Office Hadley Centre, Met Office, Exeter, EX1 3PB, UK

${ }^{6}$ Department of Statistical Modeling, Institute of Statistical Mathematics, Tachikawa, Japan

${ }^{7}$ Geography Department, Humboldt-Universität zu Berlin, Berlin, Germany

${ }^{8}$ Department Geoscience and Remote Sensing, Delft University of Technology, 2628CN Delft, the Netherlands

${ }^{9}$ Climate Institute, Delft University of Technology, 2628CN Delft, the Netherlands

${ }^{10}$ Japan Agency for Marine-Earth Science and Technology, Department of Integrated Climate Change Projection Research,

Yokohama, Japan

${ }^{11}$ Laboratoire des Sciences du Climat et de l'Environment, Gif sur Yvette, France

${ }^{12}$ University of Washington, Seattle, WA, USA

${ }^{13}$ Department of Biology, Dalhousie University, Halifax, Nova Scotia, Canada

${ }^{14}$ Nereus Program, Institute for Oceans and Fisheries, University of British Columbia, Vancouver, British Columbia, Canada

${ }^{15}$ CCSR Earth Institute, Columbia University, New York, NY, USA

${ }^{16}$ Computation Institute, University of Chicago, Chicago, IL, USA

${ }^{17}$ Institut de Ciència i Tecnologia Ambientals (ICTA) and Department of Mathematics, Universitat Autonoma de Barcelona, 08193 Barcelona, Spain

${ }^{18}$ Catalan Institution for Research and Advanced Studies (ICREA), 08010 Barcelona, Spain

${ }^{19}$ School of Geography, University of Nottingham, Nottingham, UK

${ }^{20}$ Senckenberg Biodiversity and Climate Research Centre (BiK-F), Senckenberganlage 25, 60325 Frankfurt, Germany

${ }^{21}$ Global Climate Forum, 10178 Berlin, Germany

${ }^{22}$ Division of Resource Economics, Albrecht Daniel Thaer-Institute and Berlin Workshop in Institutional Analysis of Social-Ecological Systems (WINS), Humboldt-University, Berlin, Germany

${ }^{23}$ Catalan Institute for Water Research (ICRA), Girona, Spain

${ }^{24}$ Institute of Physical Geography, Goethe-University Frankfurt, Germany

${ }^{25}$ Copernicus Institute of Sustainable Development, Utrecht University, Utrecht, the Netherlands

${ }^{26}$ Uppsala University, Department of Limnology, Uppsala, Sweden

${ }^{27}$ United Nations Environment Programme World Conservation Monitoring Centre, Cambridge, UK 
${ }^{28}$ Water Systems and Global Change group, Wageningen University, Wageningen, the Netherlands

${ }^{29}$ College of Life and Environmental Sciences, Hatherly Laboratories, Prince of Wales Road, Exeter, EX4 4PS, UK

${ }^{30}$ Climate Analytics, Berlin, Germany

${ }^{31}$ Institute for the Study of Earth, Oceans, and Space, University of New Hampshire, Durham, NH, USA

${ }^{32}$ Humboldt-Universität zu Berlin, Department of Agricultural Economics, Berlin, Germany

${ }^{33}$ International Center for Climate and Global Change Research, School of Forestry and Wildlife Sciences, Auburn

University, Auburn, AL, USA

${ }^{34}$ State Key Laboratory of Urban and Regional Ecology, Research Center for Eco-Environmental Sciences, Chinese Academy of Sciences, Beijing, 100085, China

${ }^{35}$ Center for Global Environmental Studies, National Institute for Environmental Studies, Tsukuba, Japan

Correspondence to: Katja Frieler (katja.frieler@pik-potsdam.de)

Received: 25 August 2016 - Discussion started: 20 October 2016

Revised: 4 October 2017 - Accepted: 17 October 2017 - Published: 30 November 2017

Abstract. In Paris, France, December 2015, the Conference of the Parties (COP) to the United Nations Framework Convention on Climate Change (UNFCCC) invited the Intergovernmental Panel on Climate Change (IPCC) to provide a "special report in 2018 on the impacts of global warming of $1.5^{\circ} \mathrm{C}$ above pre-industrial levels and related global greenhouse gas emission pathways". In Nairobi, Kenya, April 2016, the IPCC panel accepted the invitation. Here we describe the response devised within the Inter-Sectoral Impact Model Intercomparison Project (ISIMIP) to provide tailored, cross-sectorally consistent impact projections to broaden the scientific basis for the report. The simulation protocol is designed to allow for (1) separation of the impacts of historical warming starting from pre-industrial conditions from impacts of other drivers such as historical land-use changes (based on pre-industrial and historical impact model simulations); (2) quantification of the impacts of additional warming up to $1.5^{\circ} \mathrm{C}$, including a potential overshoot and longterm impacts up to 2299 , and comparison to higher levels of global mean temperature change (based on the lowemissions Representative Concentration Pathway RCP2.6 and a no-mitigation pathway RCP6.0) with socio-economic conditions fixed at 2005 levels; and (3) assessment of the climate effects based on the same climate scenarios while accounting for simultaneous changes in socio-economic conditions following the middle-of-the-road Shared Socioeconomic Pathway (SSP2, Fricko et al., 2016) and in particular differential bioenergy requirements associated with the transformation of the energy system to comply with RCP2.6 compared to RCP6.0. With the aim of providing the scientific basis for an aggregation of impacts across sectors and analysis of cross-sectoral interactions that may dampen or amplify sectoral impacts, the protocol is designed to facilitate consistent impact projections from a range of impact models across different sectors (global and regional hydrology, lakes, global crops, global vegetation, regional forests, global and regional marine ecosystems and fisheries, global and regional coastal infrastructure, energy supply and demand, temperature-related mortality, and global terrestrial biodiversity).

\section{Introduction}

Societies are strongly influenced by weather and climate conditions. It is generally understood that persistent weather patterns influence lifestyle, infrastructures, and agricultural practices across climatic zones. In addition, individual weather events can cause immediate economic damages and displacement. However, the precise translation of projected changes in weather and climate into societal impacts is complex and not yet fully understood or captured by predictive models (Warren, 2011). Empirical approaches have linked pure climate indicators like temperature or precipitation to highly aggregated socio-economic indicators such as national gross domestic product (GDP) (Burke et al., 2015; Dell et al., 2012), but do not resolve the underlying mechanisms. At the same time a growing array of detailed (processbased) models have been developed to translate projected changes in climate and weather into specific impacts on individual systems or processes, including vegetation cover, crop yields, marine ecosystems and fishing potentials, frequency and intensity of river floods, coastal flooding due to sea-level rise, water scarcity, distribution of vector-borne diseases, changes in biodiversity and ecosystem services, heat and cold-related mortality, labour productivity, and energy supply (e.g. hydropower potentials) or demand. These models provide a basis for a more process-based quantification of societal risks.

Traditionally, sector-specific impact models are constructed independently and do not interact (except for a few multi-sector models). However, by considering the behaviour of multiple sector-specific models within a single simulation framework, it is possible to begin to assess the integrated 
impacts of climate change. Current damages from weatherrelated natural disasters amount to about USD 95 billion per year on average over 1980-2014 (Munich Re, 2015) and, from 2008 to 2015, an estimated 21.5 million people per year were displaced by weather events (Internal Displacement Monitoring Centre and Norwegian Refugee Council, 2015) where the underlying causes are diverse: storms accounted for $51 \%$ of the economic damages of weather events, flood and mass movements induced $32 \%$, and extreme temperatures, and droughts and wildfire inflicted $17 \%$ of the overall losses. Displacement was mainly driven by floods $(64 \%)$ and storms $(35 \%)$, with minor contributions from extreme temperatures $(0.6 \%)$, wet mass movement $(0.4 \%)$, and wildfires $(0.2 \%)$ (the more indirect effects of rainfall deficits and agricultural droughts on displacement are not even captured in these global statistics of displacement). Thus, projections of fluctuations and long-term trends in the most basic proxies of immediate disaster-induced economic losses and displacements such as "exposed assets" or "number of people affected" require a range of different types of climateimpact models (e.g. hydrological models for flood risks, biomes models for risks of wildfires, crop models for heat or drought-induced crop failure), which have to be forced by the same climate input to allow for an aggregation of the respective impacts.

ISIMIP is designed to address this challenge by forcing a wide range of climate-impact models with the same climate and socio-economic input (Schellnhuber et al., 2013, www.isimip.org) and by making the data publicly available (https://www.isimip.org/protocol/terms-of-use/), similarly to the climate simulations generated within the Coupled Model Intercomparison Project (CMIP, Taylor et al., 2012). In its first phase, the ISIMIP Fast Track provided the first set of cross-sectorally consistent, multi-model impact projections (Warszawski et al., 2014). The data are publicly available through https://esg.pik-potsdam.de. Now in its second phase, the first simulation round (ISIMIP2a) was dedicated to historical simulations with a view to detailed model evaluation, in particular with respect to the impacts of extreme events. So far, over 65 international modelling groups have submitted data to the ISIMIP2a repository, which will be made publicly available in 2017. First sectoral packages of ISIMIP2a data are already available through https://esg.pik-potsdam. de. Here, we describe the simulation protocol and scientific rationale for the next round of simulations (ISIMIP2b). The protocol was developed in response to the planned IPCC Special Report on the $1.5^{\circ} \mathrm{C}$ target, reflecting the responsibility of the impact-modelling community to provide the best scientific basis for political discussions about mitigation and adaptation measures. Importantly, the simulations also offer a broad basis for climate-impact research beyond the scope and time frame of the Special Report. Given the tight timeline the ISIMIP2b data will be made publicly available according to adjusted terms of use, superseding the usual embargo period (https://www.isimip.org/protocol/terms-of-use/). In this way the ISIMIP2b simulation data can be used by a wider community to extend the scientific evidence base for the Special Report.

In Paris, parties agreed on "... holding the increase in the global average temperature to well below $2{ }^{\circ} \mathrm{C}$ above preindustrial levels and pursuing efforts to limit the temperature increase to $1.5^{\circ} \mathrm{C}$ above pre-industrial levels, recognizing that this would significantly reduce the risks and impacts of climate change." (UNFCCC, 2015). While the statement "holding below $2{ }^{\circ} \mathrm{C}$ " implies keeping global warming below the $2{ }^{\circ} \mathrm{C}$ limit over the full course of the century and afterwards, "efforts to limit the temperature increase to $1.5^{\circ} \mathrm{C}$ " is often interpreted as allowing for a potential overshoot before returning to below $1.5^{\circ} \mathrm{C}$ (Rogelj et al., 2015). Given the remaining degrees of freedom regarding the timing of maximum warming and the length of an overshoot, the translation of emissions into global mean temperature change, and, even more importantly, the uncertainty in associated regional climate changes, a wide range of climate change scenarios, all consistent with these political targets, should be considered, along with multiple ways to reach a given target. However, the computational expense of climate and climateimpact projections limits the set of scenarios that can be feasibly computed. These should therefore be carefully selected to serve as the basis for efficient extrapolations of impacts to a wider range of relevant climate-change scenarios. In the ISIMIP2b protocol, the Representative Concentration Pathway (RCP) RCP2.6 was chosen, being the lowest emission scenario considered within CMIP5 and in line with a 1.5 or $2{ }^{\circ} \mathrm{C}$ limit of global warming depending on the definition and the global circulation model (GCM) considered. While there are plans within the next phase of CMIP to generate climate projections for a lower emission scenario (RCP2.0), these data will not be available in time to make the associated impact projections for the Special Report.

The ISIMIP protocol covers a core set of scenarios that can be run by all participating impact-modelling groups, ensuring a minimal set of multi-model impact simulations consistent across sectors, and therefore allowing for cross-sectoral aggregation and integration of impacts. In Sect. 2 of the paper we outline the basic set of scenarios and the rationale for their selection. Sections 3-8 provide a more detailed description of the input data, i.e. climate input data, land use (LU) and irrigation patterns accounting for mitigation-related expansion of managed land (e.g. for bioenergy production), population and GDP data, and associated harmonized input representing other drivers on impact indicators. Section 9 provides exemplary information about the sector-specific implementation of the different scenarios for the global and regional water sector. Associated tables for the other sectors are included in the Supplement. Further technical information such as up-to-date lists of sector-specific requested output variables and detailed information about data formats, etc., is included in a separate ISIMIP2b modelling protocol on the ISIMIP website (www.isimip.org/protocol/\#isimip2b) 
that should be used as up-to-date reference by participating modelling groups when setting up and performing simulations.

\section{The rationale of the basic scenario design}

Core ISIMIP2b simulations will focus on (1) quantification of impacts of the historical warming compared to preindustrial reference levels (see Sect. 2.1, Fig. 1a, Group 1); (2) quantification of the climate change effects based on a strong mitigation pathway and a business-as-usual (BAU) pathway assuming fixed, present-day management, land-use and irrigation patterns and societal conditions (see Sect. 2.2, Fig. 1a, Group 2) including a quantification of the longterm effects of low-level global warming following a potential overshoot based on an extension of the strong mitigation pathway to 2299; and (3) quantification of the impacts of "low-level" $\left(\sim 1.5^{\circ} \mathrm{C}\right)$ global warming based on the strong mitigation and BAU pathway, while accounting for additional (human) influences such as changes in management and LU patterns in response to population growth and bioenergy demand (see Sect. 2.3, Fig. 1b, Group 3).

To ensure wide sectoral coverage by a large number of impact models, the set of scenarios is restricted to (1) the SSP2 socio-economic storyline representing middleof-the-road socio-economic development concerning population and mitigation and adaptation challenges (O'Neill et al., 2014) (see Sect. 5); (2) climate input from four GCMs (see Sect. 3); (3) simulations of the historical period, and future projections for a no-mitigation baseline scenario (SSP2 + RCP6.0) (Fricko et al., 2016) and the strong mitigation scenario (SSP2 + RCP2.6) closest to the global warming limits agreed on in Paris (see Sect. 3); and (4) representation of potential changes in LU, irrigation, and fertilizer input associated with SSP2 + RCP6.0 (LU_ISIMIP2b_ssp2_rcp60) and SSP2 + RCP2.6 (LU_ISIMIP2b_ssp2_rcp26) as generated by the global LU model MAgPIE (Model of Agricultural Production and its Impact on the Environment, LotzeCampen et al., 2008; Popp et al., 2014a; Stevanović et al., 2016) and adjusted to ensure a smooth transition from historical patterns. MAgPIE simulations account for climateinduced changes in crop production, water availability, terrestrial carbon content, and differential bioenergy application (see Sect. 4).

\subsection{Quantification of pure climate-change effects of the historical warming compared to pre-industrial reference levels (Fig. 1a, Group 1)}

The Paris Agreement explicitly asks for an assessment of "the impacts of global warming of $1.5^{\circ} \mathrm{C}$ above preindustrial levels", particularly including a quantification of impacts of the historical warming to about $\sim 1^{\circ} \mathrm{C}$. Usually, impact projections (such as those generated within the
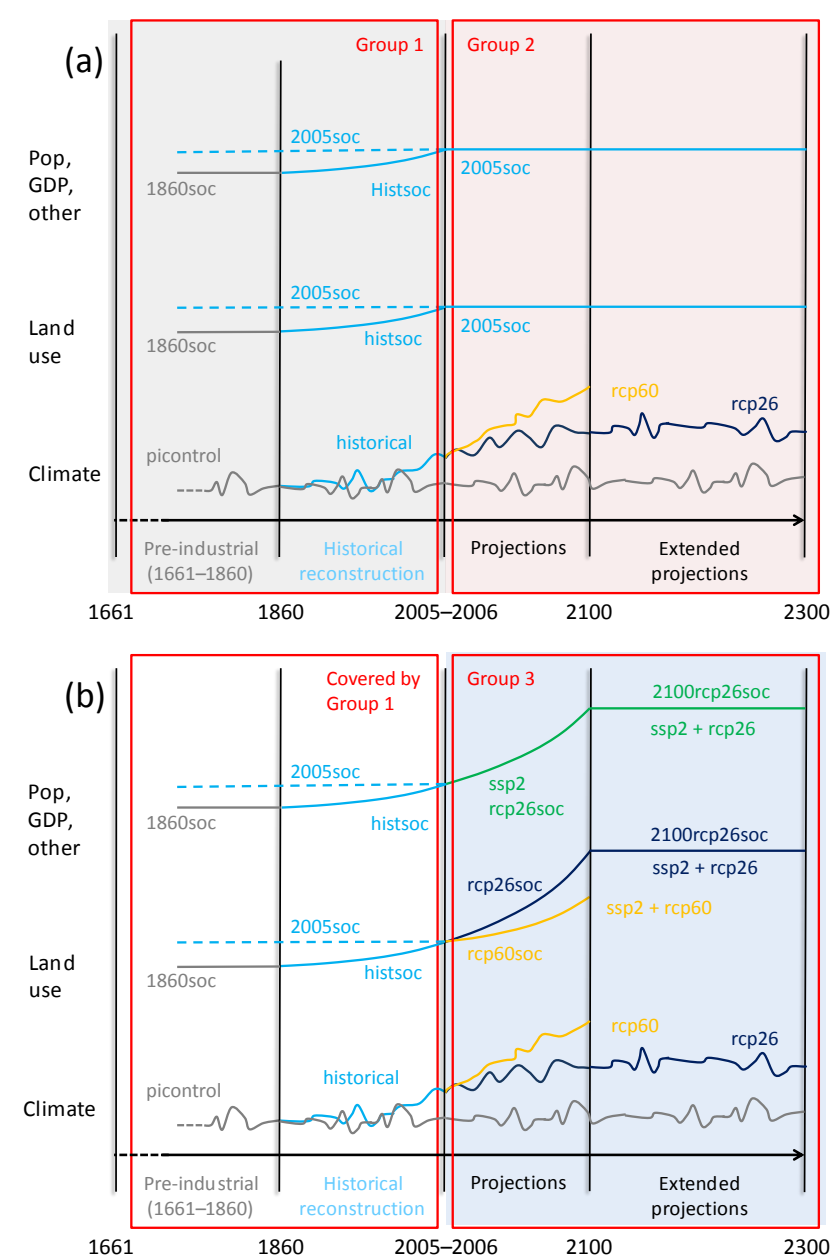

Figure 1. Schematic representation of the scenario design for ISIMIP2b. "Other" includes other non-climatic forcing factors such as fertilizer input, irrigation, selection of crop varieties, flood protection levels, dams and reservoirs, water abstraction for human use, fishing effort, atmospheric nitrogen deposition, etc. Panel (a) shows the Group 1 and Group 2 runs. Group 1 consists of model runs to separate the pure effect of the historical climate change from other (human) influences. Models that cannot account for changes in a particular forcing factor are asked to hold that forcing factor at 2005 levels (2005soc, dashed lines). Group 2 consists of model runs to estimate the pure effect of the future climate change assuming fixed year 2005 levels of population, economic development, LU, and management $(2005 \mathrm{soc})$. Panel (b) shows Group 3 runs. Group 3 consists of model runs to quantify the effects of the LU changes, and changes in population, GDP, and management from 2005 onwards associated with RCP6.0 (no mitigation scenario under SSP2) and RCP2.6 (strong mitigation scenario under SSP2). Forcing factors for which no future scenarios exist (e.g. dams/reservoirs) are held constant after 2005 .

ISIMIP Fast Track, Warszawski et al., 2014) only allow for a quantification of projected impacts (of say $1.5^{\circ} \mathrm{C}$ warming) compared to "present day" or "recent past" reference levels, because the impact model simulations rarely cover 
the pre-industrial period. This severely restricts the opportunities to gain a better understanding of climate-change impacts already unfolding and the options to address questions associated with the "detection and attribution" of historical impacts in the context of the "loss and damage" debate (James et al., 2014). In the Fifth Assessment Report of the Intergovernmental Panel on Climate Change (IPCC AR5), an entire chapter is dedicated to the detection and attribution of observed climate-change impacts (Cramer et al., 2014). However, the conclusions that can be drawn are limited by (1) the lack of long-term and homogeneous observational data, and (2) the confounding influence of other drivers such as population growth and management changes (e.g. expansion of agriculture in response to growing food demand, changes in irrigation water withdrawal, building of dams and reservoirs, changes in fertilizer input, and switching to other crop varieties) on climate-impact indicators such as river discharge, crop yields, and energy demand, etc. For the historical period these other influences may also comprise known natural disturbances such as wildfires, outbreaks of diseases, and pests, etc. that could be considered as external drivers in part of the models. However, for simplicity we refer to the entire group of external drivers as "socioeconomic conditions" throughout the paper. Over the historical period, these influences have evolved simultaneously with climate, rendering the quantification of the pure climatechange signal difficult. Model simulations could help to fill these gaps and could become essential tools to separate the effects of climate change from other historical drivers. To address these challenges, the ISIMIP2b protocol includes (1) a multi-centennial pre-industrial reference simulation (picontrol + fixed pre-industrial socio-economic conditions (1860soc), 1660-1860), (2) historical simulations accounting for varying socio-economic conditions but assuming pre-industrial climate (picontrol + histsoc, 1861-2005), and (3) historical impact simulations accounting for varying socio-economic conditions and climate change (histori$\mathrm{cal}+$ histsoc, 1861-2005). These scenarios facilitate the separation of the effects of historical warming (as simulated by GCMs) from the other drivers by taking the difference between the two model runs covering the historical period. The full period of historical simulation results also allows for cross-sectorial assessments of when the climate signal becomes significant. In addition, the control simulations will provide a large sample of pre-industrial reference conditions, allowing for robust determination of extreme-value statistics (e.g. the water levels of 100-yearly flood events) and, for example, the typical spatial distribution of impacts associated with certain large-scale circulation patterns such as El Niño (Iizumi et al., 2014; Ward et al., 2014) or other circulation regimes capable of synchronizing the occurrence of extreme events across sectors and regions (Coumou et al., 2014; Francis and Vavrus, 2012). In addition, the preindustrial reference represents more realistic starting (and spin-up) conditions for, for example, the vegetation models or marine ecosystem models, compared to artificial "equilibrium present day" conditions as used in the ISIMIP Fast Track.

For models that are not designed to represent temporal changes in LU patterns or socio-economic conditions, simulations should be based on constant present-day (year 2005) societal conditions ("2005soc", dashed line in Fig. 1). Modelling teams whose models do not account for any human influences are also invited to contribute simulations for Group 1 and Group 2 based on naturalized settings (to be labelled "nosoc"). A detailed documentation of the individual model-specific settings implemented by the different modelling groups is available in the Supplement.

\subsection{Future impact projections accounting for low and high greenhouse gas emissions, assuming present-day socio-economic conditions (Fig. 1a, Group 2)}

To quantify the pure effect of additional warming to $1.5^{\circ} \mathrm{C}$ or higher above pre-industrial levels, the scenario choice includes a group of future projections assuming socioeconomic conditions fixed at present-day (chosen to be 2005) conditions (2005soc, see Fig. 1a, Group 2). The Group 2 simulations start from the Group 1 simulations and assume (1) fixed, year 2005 socio-economic conditions but pre-industrial climate (picontrol + 2005soc, 20062099), (2) fixed year 2005 socio-economic conditions and climate change under the strong-mitigation scenario RCP2.6 (rcp26+2005soc, 2006-2099), (3) fixed year 2005 socioeconomic conditions and climate change under the nomitigation scenario RCP6.0 (rcp60 + 2005soc, 2006-2099), and (4) extension of the RCP2.6 simulations to 2299 assuming socio-economic conditions fixed at year 2005 levels (rcp26 +2005soc, 2101-2299). In this way, the distribution of impact indicators within certain time windows, in which global warming is around 1.5 or $2^{\circ} \mathrm{C}$, for example, can be compared without the confounding effects of other drivers that vary with time (e.g. Fischer and Knutti, 2015; Schleussner et al., 2015). In particular, the impacts at these future levels of warming can be compared to the pre-industrial reference climate, assuming a representation of pre-industrial levels of socio-economic conditions (picontrol +1860 soc, Group 1) and pre-industrial reference climate but present-day levels of socio-economic conditions (picontrol +2005 soc, Group 2).

The extension of the RCP2.6 projections to 2299 is important because (1) global mean temperature may only return to warming levels below $2{ }^{\circ} \mathrm{C}$ after 2100 (see HadGEM2ES and IPSL-CM5A-LR, Fig. 2), and (2) impacts of global warming will not necessarily emerge in parallel with global mean temperature change, because, for example, climate models show a hysteresis in the response of the hydrological cycle due to ocean inertia (Wu et al., 2010). Similarly, sea-level rise associated with a certain level of global warm- 
ing will only fully manifest over millennia. In addition to the lagged responses of climate to greenhouse gas emissions, there is additional inertia in the affected systems (such as vegetation changes and permafrost thawing) that will delay responses. Thus, an assessment of the risks associated with $1.5^{\circ} \mathrm{C}$ global warming requires simulations of impacts when $1.5^{\circ} \mathrm{C}$ global warming is reached, as well as of the impacts when global warming returns to $1.5^{\circ} \mathrm{C}$ and stabilizes. The characteristic peak and decline in global mean temperature associated with RCP2.6 (depending on the climate model) will help to get a better understanding of the associated impact dynamics. This could be used to derive reduced-form approximations of the complex-model simulations, allowing for a scaling of the impacts to other global-mean-temperature and $\mathrm{CO}_{2}$ pathways by, for example, identifying the functional relationships between global mean temperature change and the considered impact in the case of instantaneous responses (Hirabayashi et al., 2013) or using approaches that allow for delayed responses of the system under consideration (Mengel et al., 2016; Winkelmann and Levermann, 2013). In each case simplified models trained in RCP2.6 could be tested on RCP6.0. Providing the basis for the development of these tools is critical given the range of scenarios consistent with the temperature goals as described in the Paris agreement.

Depending on the timescale of stabilization of the climate and the lag in the response of the impacts to climate change, the extension of the simulations to 2299 could provide a sample of a relatively stable distribution of impacts associated with RCP2.6 levels of emissions. Similar to the 200-year pre-industrial reference simulations, this sample could provide a basis for the estimation of extreme-value distributions that can be compared to the associated pre-industrial reference distributions (picontrol +1860 soc - Group 1, or picontrol +2005 soc - Group 2).

\subsection{Future impact projections accounting for low and high levels of climate change accounting for socioeconomic changes (Fig. 1b, Group 3)}

Future projections of the impacts of climate change also depend on future socio-economic development. For example many impact indicators such as "number of people affected by flood events" (Hirabayashi et al., 2013) or "number of people affected by long-term changes going beyond a certain range of the reference distribution" (Piontek et al., 2014) directly depend on population projections (exposure) or socioeconomic conditions, e.g. reflected in flood protection levels (vulnerability). While socio-economic drivers can partly be accounted for in post-processing (e.g. for the number of people affected by tropical cyclones), others are directly represented in the models, such as dams and reservoirs or LU changes. To capture the associated effects on the impact indicators, the ISIMIP2b protocol contains a set of future projections accounting for potential changes in socio-economic conditions (e.g. rcp26soc), building on the SSP2 story line (see Fig. 1b, Group 3). The relevance and representation of specific socio-economic drivers strongly differs from sector to sector or impact model to impact model. Here, we focus on changes (1) in population patterns and national GDP (see Sect. 6); (2) land-use, irrigation patterns and fertilizer input (see Sect. 4); and (3) nitrogen deposition (see Sect. 7). However, even beyond these indicators, models that represent other individual drivers should account for associated changes according to their own implementation of the SSP2 storyline. The simulations start from the Group 1 simulations and assume (1) future changes in human influences but pre-industrial climate (picontrol + rpc26soc or rcp60soc, 2006-2099), (2) future changes in human influences and climate change under the strong mitigation scenario RCP2.6 (rcp26 + rcp26soc, 2006-2099), (3) future changes in human influences and climate change under the no-mitigation scenario RCP6.0 (rcp60 + rcp60soc, 2006-2099), and (4) and extension of the RCP2.6 simulations to 2299 assuming human influences fixed at 2100 levels (rcp26+2100rcp26soc, 2101-2299).

The representation of changes in LU, irrigation, and fertilizer input is particularly challenging as it should be consistent with historical records, and future changes are affected by multiple factors including (1) population growth, (2) changing diets under economic development, (3) climatechange effects on crop yields, and (4) bioenergy demand associated with the level of climate change mitigation. The ISIMIP2b protocol is designed to account for all these aspects (see Sect. 4). Using associated LU patterns in the impact models participating in ISIMIP2b will allow for the assessment of potential side effects of certain transformations of the energy system associated with a $1.5^{\circ} \mathrm{C}$ global-meantemperature limit, such as the allocation of land areas to bioenergy production. The scenario design will facilitate estimation of the consequences of the suggested LU changes in comparison to the avoided impacts of climate change.

\section{Climate input data}

Bias-adjusted climate input data at daily temporal and $0.5^{\circ}$ horizontal resolution representing pre-industrial, historical, and future (RCP2.6 and RCP6.0) conditions will be provided based on CMIP5 output of GFDL-ESM2M, HadGEM2ES, IPSL-CM5A-LR, and MIROC5. Output from the first three of these four GCMs was already used in the ISIMIP Fast Track. In contrast to the ISIMIP Fast Track we will also provide bias-adjusted atmospheric data over the ocean, which is, for example, relevant for the impacts on offshore wind energy generation or the physical representation of coastal flooding. Output from two of the GCMs (GFDL-ESM2M and IPSL-CM5A-LR) includes the physical and biogeochemical ocean data required by the marine ecosystem sector of ISIMIP (see FISH-MIP, www. 


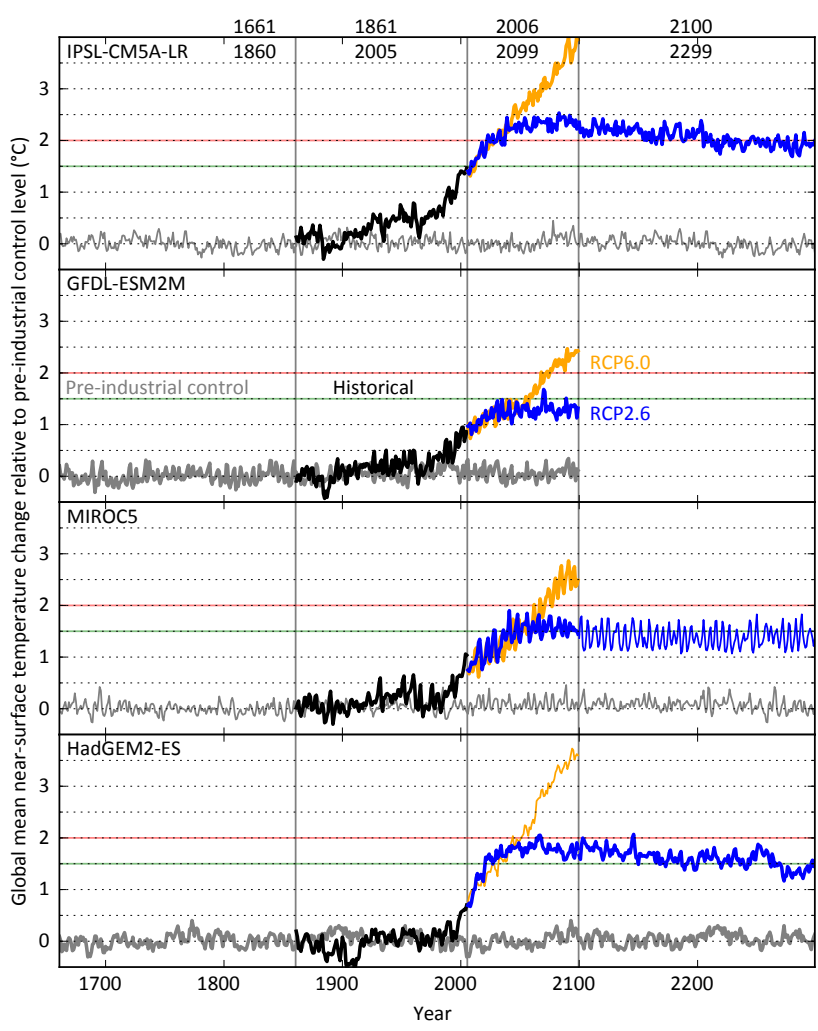

Figure 2. Time series of annual global mean near-surface temperature change relative to pre-industrial levels (1661-1860) as simulated with IPSL-CM5A-LR, GFDL-ESM2M, MIROC5 and HadGEM2-ES (from top to bottom). Colour coding indicates the underlying CMIP5 experiments (grey: pre-industrial control, black: historical, blue: RCP2.6, yellow: RCP6.0) with corresponding time periods given at the top. Thick lines indicate model-experiment combinations for which 3-hourly climate input data are available (see Table 2).

isimip.org/gettingstarted/marine-ecosystems-fisheries/). The fast-track model NorESM1-M was taken out of the selection due to the unavailability of near-surface wind data, and MIROC-ESM-CHEM was replaced by MIROC5, which in comparison features twice the horizontal atmospheric resolution (Watanabe et al., 2010, 2011), a lower equilibrium climate sensitivity (Flato et al., 2013), a smaller temperature drift in the pre-industrial control run $\left(0.36^{\circ} \mathrm{C} \mathrm{ka}^{-1}\right.$ compared to $0.93{ }^{\circ} \mathrm{C} \mathrm{ka}^{-1}$ ), and more realistic representations of ENSO (Bellenger et al., 2014), the Asian summer monsoon (Sperber et al., 2013), and North Atlantic extratropical cyclones (Zappa et al., 2013) during the historical period.

GCM selection was heavily constrained by CMIP5 data availability since we employed a strict climate input data policy to facilitate unrestricted cross-sectoral impact assessments. In order to be included in the selection, daily CMIP5 GCM output had to be available for the atmospheric variables listed in Table 1 covering at least 200 pre-industrial control years, the whole historical period from 1861 to 2005 , and RCP2.6 and RCP6.0 from 2006 to 2099 each. Originally, these requirements were completely met for GFDL-ESM2M, IPSL-CM5A-LR, and MIROC5. Gaps in HadGEM2-ES data were filled by re-running the model accordingly.

The small number of only four GCMs is not sufficient to span the range of regional climate changes projected by the entire CMIP5 ensemble. Figures S7 and S8 of the Supplement allow for a comparison of the regional temperature and precipitation changes as projected by the selected GCMs to the projections of the entire CMIP5 ensemble of GCMs. The comparison is provided for all ISIMIP2b focus regions (see Fig. 6) that will be covered by regional hydrological simulations (selected river basins) and simulations of changes in marine ecosystems and fisheries (selected ocean sections). Figure S9 provides an additional analysis of the fractional range coverage (FRC; McSweeney and Jones, 2016) of these regional climate change signals by the ISIMIP2b set of GCMs. While originally chosen on the basis of climate input data requirements, the four selected GCMs provide an FRC close to the mean FRC across randomly chosen four-member sets of CMIP5 GCMs.

Data from IPSL-CM5A-LR and GFDL-ESM2M are the first- and second-priority climate input datasets respectively, since these GCMs provide all the monthly ocean data required by FISH-MIP and since IPSL-CM5A-LR additionally offers an extended RCP2.6 projection. That means impactmodelling groups that do not have the capacities to do all simulations described in the ISIMIP2b protocol should start to force their model by the IPSL-CM5A-LR data and then continue with the GFDL-ESM2M runs if possible. Usage of MIROC5 data is of third priority. Since the HadGEM2-ES climate input data only became available at a later stage in the project, it is the fourth priority.

Global-mean-temperature projections from IPSL-CM5ALR and HadGEM2-ES under RCP2.6 exceed $1.5^{\circ} \mathrm{C}$ relative to pre-industrial levels in the second half of the 21 st century (see Fig. 2). While global-mean-temperature change returns to $1.5^{\circ} \mathrm{C}$ or even slightly lower by 2299 in HadGEM2-ES, it only reaches about $2{ }^{\circ} \mathrm{C}$ in IPSL-CM5A-LR by 2299 . For GFDL-ESM2M, global-mean-temperature change stays below $1.5^{\circ} \mathrm{C}$ until 2100 . For MIROC5, it stabilizes at about $1.5^{\circ} \mathrm{C}$ during the second half of the 21 st century.

For HadGEM2-ES, IPSL-CM5A-LR, and MIROC5, it was necessary to recycle pre-industrial control climate data in order to fill the entire 1661-2299 period. Based on available data, the recycled time series start after the first 320 (HadGEM2-ES), 440 (IPSL-CM5A-LR), and 570 (MIROC5) pre-industrial control years, which means that pre-industrial control climate data from 1981, 2101, and 2231 onwards are identical to those from 1661 onwards, respectively. For GFDL-ESM2M, no such recycling was necessary. For all four GCMs, temperature drifts in the preindustrial control run are considered sufficiently small relative to inter-annual variability and temperature changes in 
the historical and future periods, so that de-trending preindustrial control climate data was deemed unnecessary.

\subsection{Bias-adjusted atmospheric GCM data}

For most variables, the provided atmospheric GCM data have been bias-adjusted using slightly modified versions of the ISIMIP fast-track methods, which adjust multi-year monthly mean values, such that trends are preserved in absolute and relative terms for temperature and non-negative variables, respectively, and derive transfer functions to adjust the distributions of daily anomalies from monthly mean values (Hempel et al., 2013). Known issues of the fast-track methods are as follows: (1) humidity was not adjusted since the methods were not designed for variables with both lower and upper bounds, such as relative humidity, and since their application to specific humidity yields relative humidity statistics that compare poorly with those observed; (2) bias-adjusted daily mean shortwave radiation values too frequently exceed $500 \mathrm{~W} \mathrm{~m}^{-2}$ over Antarctica and high-elevation sites; (3) for pressure, wind speed, and longwave and shortwave radiation they produce noticeable discontinuities in daily climatologies at each turn of the month, similar to those found by Rust et al. (2015); (4) they occasionally generate spuriously high precipitation events in semi-arid regions; and (5) they do not adjust the inter-annual variability of monthly mean values, which would be an important improvement for the purpose of impact projections (Sippel et al., 2016). While (5) and (4) are items of future work, problems (3), (2), and (1) were solved through modifications of the methods of adjustment for pressure, wind speed, and longwave radiation, and by using newly developed, approximately trend-preserving bias adjustment methods for relative humidity and shortwave radiation (see below). The known issues and their solutions are described in more detail in an associated fact sheet (https: //www.isimip.org/gettingstarted/isimip2b-bias-correction/).

In addition to these adjustments, we bias-adjust to a new reference dataset. While in the Fast Track, WATCH forcing data (Weedon et al., 2011) were employed for bias adjustment, the ISIMIP2b forcing data are adjusted to the newly compiled reference dataset EWEMBI (E2OBS, WFDEI and ERAI data merged and bias-corrected for ISIMIP; Lange, 2016), which covers the entire globe at $0.5^{\circ}$ horizontal and daily temporal resolution from 1979 to 2013. Data sources of EWEMBI are ERA-Interim reanalysis data (ERAI; Dee et al., 2011), WATCH forcing data methodology applied to ERA-Interim reanalysis data (WFDEI; Weedon et al., 2014), eartH2Observe forcing data (E2OBS; Dutra, 2015), and NASA/GEWEX Surface Radiation Budget data (SRB; Stackhouse Jr. et al., 2011). The SRB data were used to biasadjust E2OBS shortwave and longwave radiation using a new method that has been developed particularly for this purpose (Lange, 2017) in order to reduce known deviations of E2OBS radiation statistics from the respective SRB estimates over tropical land (Dutra, 2015). Data sources of individual EWEMBI variables are given in Table 1.

The bias adjustment was performed on the regular $0.5^{\circ}$ EWEMBI grid, to which raw CMIP5 GCM data were interpolated with a first-order conservative remapping scheme (Jones, 1999). GCM-to-EWEMBI transfer-function coefficients were calculated based on GCM data from the historical and RCP8.5 CMIP5 experiments representing the periods 1979-2005 and 2006-2013, respectively.

The variables pr, prsn, rlds, sfcWind, tas, tasmax, and tasmin were bias-adjusted as described by Hempel et al. (2013), except that we defined dry days using a modified threshold value of $0.1 \mathrm{mmday}^{-1}$, since this value was used to adjust WFDEI dry-day frequencies (Harris et al., 2013; Weedon et al., 2014). Also, in order to prevent the bias adjustment from creating unrealistically extreme temperatures, we introduced a maximum value of 3 for the adjustment factors of tas - tasmin and tas$\max -$ tas (see Hempel et al., 2013, Eq. 25) and limited tas, tasmin, and tasmax to the range $\left[-90,60^{\circ} \mathrm{C}\right]$. These limits are in line with -89.2 and $54.0^{\circ} \mathrm{C}$, the lowest and highest near-surface temperatures ever recorded on Earth if the 1913 Death Valley reading of $56.7{ }^{\circ} \mathrm{C}$ and other similarly controversial observations beyond $54.0^{\circ} \mathrm{C}$ are taken out of consideration (https://wmo.asu.edu/\#global, https://www.wunderground.com/blog/weatherhistorian/ hottest-reliably-measured-air-temperatures-on-earth.html). Lastly, in order to avoid discontinuities in daily climatologies of bias-adjusted rlds and sfcWind at the end of each month, a slightly adjusted version of the approach used to interpolate between monthly transfer function coefficients in the adjustment methods for tas, tasmax, and tasmin (Hempel et al., 2013, Eqs. 16-20) is now also applied to the adjustment factor of multi-year monthly mean rlds and sfcWind (Hempel et al., 2013, Eq. 4) in the adjustment methods for these variables.

Bias-adjusted surface pressure was obtained from CMIP5 output of sea-level pressure (psl) in three steps. First, EWEMBI ps was reduced to EWEMBI psl using EWEMBI tas, WFDEI surface elevation over land except Antarctica and ERAI surface elevation for Antarctica, and

$\mathrm{psl}=\mathrm{ps} \cdot \exp \left[\frac{g \cdot z}{R \cdot \operatorname{tas}}\right]$,

where $z$ is surface elevation, $g$ is gravity, and $R$ is the specific gas constant of dry air. Simulated psl was then adjusted using EWEMBI psl and the tas adjustment method described by Hempel et al. (2013). Finally, the bias-adjusted psl was transformed to a bias-adjusted ps using Eq. (1) with WFDEI and ERAI surface elevation and bias-adjusted tas.

As alluded to above, rsds was bias-adjusted using a newly developed method which respects the lower and upper physical limits of this variable. The new method fits beta distributions to the observed and simulated daily rsds data and then transforms the simulated data based on these fitted dis- 
Table 1. Data sources of individual variables of the EWEMBI dataset (Lange, 2016). Note that E2OBS data are identical to WFDEI over land and ERAI over the ocean, except for precipitation over the ocean, which was bias-adjusted using GPCPv2.1 monthly precipitation totals (Balsamo et al., 2015; Dutra, 2015). WFDEI-GPCC means WFDEI with GPCCv5 and v6 monthly precipitation totals used for bias adjustment (Weedon et al., 2014; note that the WFDEI precipitation products included in E2OBS were those that were bias-adjusted with CRU TS3.101/TS3.21 monthly precipitation totals). E2OBS-SRB means E2OBS with SRB daily mean radiation used for bias adjustment (Lange, 2017). E2OBS-ERAI means E2OBS everywhere except over Greenland and Iceland (see Weedon et al., 2010, p. 9), where monthly mean diurnal temperature ranges were restored to those of ERAI using the Sheffield et al. (2006) method. Note that precipitation here means total precipitation, i.e. rainfall plus snowfall.

\begin{tabular}{|c|c|c|c|c|}
\hline Variable & Short name & Unit & $\begin{array}{l}\text { Source dataset } \\
\text { over land }\end{array}$ & $\begin{array}{l}\text { Source dataset } \\
\text { over the ocean }\end{array}$ \\
\hline Near-surface relative humidity & hurs & $\%$ & E2OBS & E2OBS \\
\hline Near-surface specific humidity & huss & $\mathrm{kg} \mathrm{kg}^{-1}$ & E2OBS & E2OBS \\
\hline Precipitation & $\mathrm{pr}$ & $\mathrm{kg} \mathrm{m}^{-2} \mathrm{~s}^{-1}$ & WFDEI-GPCC & E2OBS \\
\hline Snowfall flux & prsn & $\mathrm{kg} \mathrm{m}^{-2} \mathrm{~s}^{-1}$ & WFDEI-GPCC & E2OBS \\
\hline Surface pressure & ps & $\mathrm{Pa}$ & E2OBS & E2OBS \\
\hline Sea-level pressure & psl & $\mathrm{Pa}$ & E2OBS & E2OBS \\
\hline Surface downwelling longwave radiation & rlds & $\mathrm{Wm}^{-2}$ & E2OBS-SRB & E2OBS-SRB \\
\hline Surface downwelling shortwave radiation & rsds & $\mathrm{W} \mathrm{m}^{-2}$ & E2OBS-SRB & E2OBS-SRB \\
\hline Near-surface wind speed & sfcWind & $\mathrm{ms}^{-1}$ & E2OBS & E2OBS \\
\hline Near-surface air temperature & tas & $\mathrm{K}$ & E2OBS & E2OBS \\
\hline Daily maximum near-surface air temperature & tasmax & $\mathrm{K}$ & E2OBS-ERAI & E2OBS \\
\hline Daily minimum near-surface air temperature & tasmin & $\mathrm{K}$ & E2OBS-ERAI & E2OBS \\
\hline
\end{tabular}

tributions via quantile mapping as described by Lange et al. (2017). Reflecting the physical limits of rsds, the lower bounds of the beta distributions were set to zero and their upper bounds were estimated by rescaled climatologies of downwelling shortwave radiation at the top of the atmosphere. Details of the distribution fitting are given in Lange (2017; method BCsda1). Approximate trend preservation was achieved as follows. Let $F_{\text {ref }}^{\text {to }}, F_{\text {ref }}^{\text {from }}$, and $F_{\text {other }}^{\text {from denote }}$ the beta distributions fitted to rsds observed during the reference period, simulated during the reference period, and simulated during any other period, respectively. Then the target beta distribution used for quantile mapping of simulated rsds during that other period, $F_{\text {other }}^{\text {to }}$, was defined by transferring differences between $F_{\text {ref }}^{\text {from }}$ and $F_{\text {other }}^{\text {from }}$ to differences between $F_{\text {ref }}^{\text {to }}$ and $F_{\text {other. }}^{\text {to }}$. Specifically, let $x, m$ and $v$ denote the upper bound, the relative mean value ( $m=\mu / x$, where $\mu$ is the mean value), and the relative variance $\left(v=\sigma^{2} /(\mu(x-\mu))\right.$, where $\mu$ and $\sigma$ are mean value and standard deviation, respectively) of a beta distribution. Then $0 \leq m \leq 1$ and $0 \leq$ $v \leq 1$ (Wilks, 1995), and we defined the upper bound of $F_{\text {other }}^{\text {to }}$ by

$x_{\text {other }}^{\text {to }}=\left\{\begin{array}{ll}0, & x_{\text {ref }}^{\text {from }}=0 \\ x_{\text {ref }}^{\text {to }} x_{\text {other }}^{\text {from }} / x_{\text {ref }}^{\text {from }}, & x_{\text {ref }}^{\text {from }}>0\end{array}\right.$,

its relative mean value by

$$
m_{\text {other }}^{\text {to }}= \begin{cases}m_{\text {ref }}^{\text {to }}, & m_{\text {other }}^{\text {from }}=m_{\text {ref }}^{\text {from }} \\ m_{\text {rof }}^{\text {to }} m_{\text {other }}^{\text {from }} / m_{\text {ref }}^{\text {from }}, & m_{\text {other }}^{\text {from }}<m_{\text {ref }}^{\text {frof }}, \\ 1-\left(1-m_{\text {ref }}^{\text {to }}\right)\left(1-m_{\text {other }}^{\text {from }}\right) /\left(1-m_{\text {ref }}^{\text {from }}\right), & m_{\text {other }}^{\text {from }}>m_{\text {ref }}^{\text {from }}\end{cases}
$$

and its relative variance, $v_{\mathrm{other}}^{\text {to }}$, in the same way as the relative mean value, i.e. using Eq. (3) with $m$ replaced by $v$.

Using beta distributions with fixed lower and upper bounds of 0 and $100 \%$, respectively, the new rsds bias adjustment method was also applied to hurs. A bias-adjusted huss consistent with bias-adjusted hurs, ps, and tas was calculated using the equations of Buck (1981) as described in Weedon et al. (2010). In contrast to the ISIMIP Fast Track, we decided against adjusting the wind components uas and vas to match the adjusted total daily mean velocity, as the calculation of the total velocity from wind components is nonlinear, i.e. the total velocity calculated from daily means of the wind components is not equal to the daily mean of total wind velocities. A suitable solution was not found at the time of the study. Therefore, the inconsistency has to be kept in mind when comparing models using adjusted total wind velocity to others using non-adjusted wind components. Information about the input data used by the individual impact models will be documented on the ISIMIP website (https://www.isimip.org/impactmodels/). We provide unadjusted 3-hourly sea-level pressure and near-surface eastward and northward wind data as relevant for the costal infrastructure and energy sector, for example (see Table 2).

\subsection{Tropical cyclones}

The input dataset comprises projections of tropical cyclones based on the dynamical downscaling technique described in detail by Emanuel et al. (2008). To generate a large sample of potential cyclone tracks and wind speeds the underlying model is provided with unadjusted depth-resolved seawater 
Table 2. Sub-daily GCM data (not bias-adjusted) and tropical cyclone information provided within ISIMIP2b.

\begin{tabular}{llll}
\hline Variable & Short name & Unit & Temporal resolution \\
\hline \multicolumn{1}{l}{ Atmospheric variables (e.g. for coastal } & infrastructure & or energy sector) \\
\hline Sea-level pressure & psl & $\mathrm{Pa}$ & 3 hourly \\
Eastward near-surface wind & uas & $\mathrm{ms}^{-1}$ & 3 hourly \\
Northward near-surface wind & vas & $\mathrm{m} \mathrm{s}^{-1}$ & 3 hourly \\
\hline \multicolumn{4}{l}{ Tropical cyclone information (e.g. for coastal infrastructure sector) } \\
\hline Latitude of cyclone centre & latstore & degrees & 2 hourly \\
Longitude of cyclone centre & longstore & degrees & 2 hourly \\
Minimum central pressure & pstore & $\mathrm{hPa}$ & 2 hourly \\
1 min maximum sustained wind speed & vstore & $\mathrm{m} \mathrm{s}^{-1}$ & 2 hourly \\
Radius of maximum winds & rmstore & $\mathrm{km}$ & 2 hourly \\
Expected number of cyclones per year & freqyear & \multicolumn{3}{l}{ annual } \\
\hline
\end{tabular}

potential temperature, sea surface temperature, air temperature, and specific humidity at all atmospheric model levels, as well as eastward and northward wind at 250 and $850 \mathrm{hPa}$ levels.

Broadly, the technique begins by randomly seeding with weak proto-cyclones the large-scale, time-evolving state given by the GCM climate model data. These seed disturbances are assumed to move with the GCM-provided largescale flow in which they are embedded, plus a westward and poleward component owing to planetary curvature and rotation. Their intensity is calculated using the Coupled Hurricane Intensity Prediction System (CHIPS; Emanuel et al., 2004), a simple axisymmetric hurricane model coupled to a reduced upper ocean model to account for the effects of upper ocean mixing of cold water to the surface. Applied to the synthetically generated tracks, this model predicts that a large majority of the disturbances dissipate owing to unfavourable environments. Only the "fittest" storms survive; thus the technique relies on a kind of natural selection. Extensive comparisons to historical events by Emanuel et al. (2008) and subsequent papers provide confidence that the statistical properties of the simulated events are in line with those of historical tropical cyclones. Seeding is adjusted to provide a sample of 300 potential realizations of tropical cyclones globally each year and for each of the selected GCMs, for the historical period (1950-2005), and RCP2.6 and RCP6.0 based future projections (2006-2099), yielding a total of 16800 simulated tropical cyclones for each model in the historical period, and 28500 simulated cyclones per model and future scenario. In addition, we derive the expected global number of tropical cyclones for each year. The response to global warming of both the frequency and intensity of the synthetic events compares favourably to that of more standard downscaling methods applied to the Coupled Model Intercomparison Project 3 (CMIP3) generation of climate models (Christensen et al., 2013).

\subsection{Oceanic data}

In order to cover the special data needs of FISH-MIP, we additionally provide unadjusted depth-resolved, depthintegrated, surface, and bottom oceanic data at monthly temporal resolution (see Table 3).

\section{Land-use patterns}

The second component of the request for the $1.5^{\circ} \mathrm{C}$ special report refers to an assessment of "related global greenhouse gas emission pathways". ISIMIP2b will address this issue by assessing the impacts of the socio-economic changes associated with the considered RCPs insofar as they are reflected in LU and agricultural management changes (irrigation and fertilizer input).

Future projections of LU, irrigation fractions, and fertilizer input are based on the LU model MAgPIE (Popp et al., 2014a; Stevanović et al., 2016), in which bioenergy demand and greenhouse gas prices were provided by the REMINDMAgPIE assessment, assuming population growth and economic development according to the SSP2 storyline (Popp et al., 2017). LU patterns derived by MAgPIE are designed to ensure demand-fulfilling food production where demand is externally prescribed based on an extrapolation of historical relationships between population and GDP on national levels (Bodirsky et al., 2015). In contrast to the standard SSP scenarios generated within an Integrated Assessment Model scenario process (Riahi et al., 2017), LU changes assessed for ISIMIP2b additionally account for climate and atmospheric $\mathrm{CO}_{2}$ fertilization effects on the underlying patterns of potential crop yields, water availability, and terrestrial carbon content. To this end the underlying crop, water, and biomes simulations by the LPJmL (Lund-Potsdam-Jena managed land) model are forced by atmospheric $\mathrm{CO}_{2}$ concentrations and patterns of climate change associated with RCP6.0 or RCP2.6, respectively. Potential crop production under rain- 
Table 3. Monthly oceanic data provided without bias adjustment for marine ecosystems \& fisheries sector.

\begin{tabular}{|c|c|c|}
\hline Variable & Short name & Unit \\
\hline $\begin{array}{ll}\text { Depth-resolved } & \text { monthly } \\
\text { mean seawater } & \text { potential } \\
\text { temperature } & \end{array}$ & thetao & $\mathrm{K}$ \\
\hline Sea surface temperature & tos & $\mathrm{K}$ \\
\hline Seawater $X$ velocity & uo & $\mathrm{ms}^{-1}$ \\
\hline Seawater $Y$ velocity & vo & $\mathrm{ms}^{-1}$ \\
\hline Seawater $Z$ velocity & wo & $\mathrm{ms}^{-1}$ \\
\hline Seawater temperature & to & $\mathrm{K}$ \\
\hline $\begin{array}{l}\text { Dissolved oxygen concen- } \\
\text { tration }\end{array}$ & $\mathrm{o} 2$ & $\mathrm{~mol} \mathrm{~m}^{-3}$ \\
\hline $\begin{array}{l}\text { Total primary organic car- } \\
\text { bon production (by all types } \\
\text { of phytoplankton), calcu- } \\
\text { lated as sum of lpp + spp } \\
\text { (IPSL-CM5A-LR) or sum } \\
\text { of lpp + spp + dpp (GFDL- } \\
\text { ESM2M) }\end{array}$ & intpp & $\mathrm{molCm}^{-2} \mathrm{~s}^{-1}$ \\
\hline $\begin{array}{l}\text { Small phytoplankton pro- } \\
\text { ductivity }\end{array}$ & spp & $\operatorname{molCm} \mathrm{m}^{-3} \mathrm{~s}^{-1}$ \\
\hline $\begin{array}{l}\text { Large phytoplankton pro- } \\
\text { ductivity }\end{array}$ & lpp & $\mathrm{molCm}^{-3} \mathrm{~s}^{-1}$ \\
\hline $\begin{array}{l}\text { Diazotroph primary pro- } \\
\text { ductivity }\end{array}$ & dpp & $\mathrm{molCm}^{-3} \mathrm{~s}^{-1}$ \\
\hline $\begin{array}{l}\text { Total phytoplankton car- } \\
\text { bon concentration (sum of } \\
\text { lphy + sphy (IPSL-CM5A- } \\
\text { LR) or lphy + sphy + dphy } \\
(\text { GFDL-ESM2M)) }\end{array}$ & phy & $\mathrm{molCm}^{-3}$ \\
\hline $\begin{array}{l}\text { Small phytoplankton car- } \\
\text { bon concentration }\end{array}$ & sphy & $\mathrm{molCm}^{-3}$ \\
\hline $\begin{array}{l}\text { Large phytoplankton car- } \\
\text { bon concentration }\end{array}$ & lphy & $\mathrm{molCm}^{-3}$ \\
\hline $\begin{array}{l}\text { Diazotroph carbon concen- } \\
\text { tration }\end{array}$ & dphy (diaz) & $\mathrm{molCm}^{-3}$ \\
\hline $\begin{array}{l}\text { Total zooplankton carbon } \\
\text { concentration }(1 z o o+\text { szoo })\end{array}$ & zooc & $\mathrm{molCm}^{-3}$ \\
\hline $\begin{array}{l}\text { Small zooplankton carbon } \\
\text { concentration }\end{array}$ & szoo & $\mathrm{molCm}^{-3}$ \\
\hline $\begin{array}{l}\text { Large zooplankton carbon } \\
\text { concentration }\end{array}$ & lzoo & $\mathrm{molCm}^{-3}$ \\
\hline $\mathrm{pH}$ & $\mathrm{ph}$ & 1 \\
\hline Seawater salinity & so & psu \\
\hline Sea ice fraction & $\operatorname{sic}$ & $\%$ \\
\hline $\begin{array}{l}\text { Large size-class particulate } \\
\text { organic carbon pool }\end{array}$ & goc & $\mathrm{mmolCm}^{-3}$ \\
\hline $\begin{array}{l}\text { Photosynthetically active } \\
\text { radiation }\end{array}$ & Par & einsteins $\mathrm{m}^{-2}$ day $^{-1}$ \\
\hline
\end{tabular}

fed conditions as well as full irrigation was generated by the global gridded crop component of LPJmL within the ISIMIP Fast Track (Rosenzweig et al., 2014) and used by MAgPIE to derive LU patterns under cost optimization (see time series of the MAgPIE total cropland - irrigated versus nonirrigated - in the Supplement). Projections of climate change are taken from the four GCMs also used to force the other impact projections within ISIMIP2b to ensure maximum consistency. As the MIROC5 climate input data were not part of the ISIMIP Fast Track, the associated crop yield projections by LPJmL were generated from MIROC 5 climate analogously to the Fast Track simulations to calculate the associated LU patterns. Under an SSP2 storyline and based on the REMIND-MAgPIE Integrated Assessment Modelling Framework, RCP6.0 represents a BAU greenhouse gas concentration pathway without explicit mitigation measures for the reduction of greenhouse gas emissions (Riahi et al., 2016). Given lower emission targets, REMIND-MAgPIE is designed to derive an optimal mitigation mix under climatepolicy settings, maximizing aggregate social consumption across the 21st century. To reach the low-emissions RCP2.6 scenario from an RCP6.0 reference pathway, land-based mitigation measures are of great importance (Popp et al., 2014b, 2017). The REMIND-MAgPIE framework accounts for reduced emissions from LU change via avoided deforestation, reduction of non- $\mathrm{CO}_{2}$ emissions from agricultural production, and a strong expansion of bioenergy production partly combined with carbon capture and storage (BECCS, see total land area used for second-generation bioenergy production in Fig. 3).

Historical LU patterns to be used for the Group 1 simulations were taken from the new LUH2 land-use history reconstruction (Hurtt et al., 2017) based on agricultural land area from HYDE3.2 (Klein Goldewijk, 2016), the Food and Agriculture Organization of the United Nations (2016), Monfreda et al. (2008), and other sources. The MAgPIE projections do not transition continuously from the LUH2 historical dataset (see Supplement). To ensure a smooth transition from historical LU patterns used for the historical ISIMIP2b Group 1 simulations to the future LU patterns used for the ISIMIP2b Group 3 impact projections, we applied the harmonization method developed within the context of CMIP6 (LUH2, Hurtt et al., 2017). To highlight the difference in underlying LU projections and additional adjustments described below, the LU, irrigation, and fertilizer dataset provided within ISIMIP2b should be referred to as LUH2-ISIMIP2b compared to the LUH2 data generated for CMIP6. The RCP-specific patterns should be referred to as "landuse_ISIMIP2b_ssp2_rcp26" and "landuse_ISIMIP2b_ssp2_rcp60", respectively.

The harmonization method ensures that future projections start from the end of the historical reconstruction and attempts to preserve absolute changes at various spatial scales for key variables including areas of cropland, pastures, urban land, and area used for bioenergy, irrigated areas, and relative changes in fertilizer rates (per crop type and ha) (see Fig. 3 for global areas of (1) rainfed food-feed crops, (2) irrigated food-feed crops, (3) rainfed bioenergy crops, and (4) irrigated bioenergy crops and see the Supplement for a comparison to the original areas provided by MAgPIE).The changes in total irrigated and rainfed cropland and the to- 
tal area for bioenergy generation in the harmonized dataset are quite similar to the associated changes in total areas derived from the original MAgPIE simulations (see Supplement) even though the harmonization method is not designed to generate convergence from historical patterns to the original patterns provided by MAgPIE.

The harmonization method provides a large number of LU-related information. Only part of the information is used within ISIMIP2b and therefore added to the LUH2ISIMIP2b dataset. It comprises LU, irrigation, and fertilization information on two different levels of aggregation. On the first level we provide the fraction of each grid cell covered by the following types of land use and management: (1) pastures (pastures), (2) urban land (urbanareas), (3) $\mathrm{C}_{3}$ annual crops (c3ann), (4) $\mathrm{C}_{3}$ perennial crops (c3per), (5) $\mathrm{C}_{4}$ annual crops (c4ann), (6) $\mathrm{C}_{4}$ perennial crops (c4per), (7) $\mathrm{C}_{3}$ nitrogen-fixing crops (c3nfx), (8) bioenergy grass (bioenergy_grass), and (9) bioenergy trees (bioenergy_trees). The c3per, c4per, c3ann, c4ann, c3nfx, bioenergy_grass, and bioenergy_trees classes are additionally split up into irrigated and rainfed fractions. For each crop type there is additional information about nitrogen fertilizer input per hectare. The original harmonization method only provides the fractions of each grid cell covered by c3per, c4per, c3ann, c4ann, and $\mathrm{c} 3 \mathrm{nfx}$ and additional information about the fraction of overall cropland used for second-generation biofuel plantations. However, the latter fraction is not explicitly attributed to these classes. To allow for an implementation of bioenergy crops in the impact simulations implementation we explicitly separate land areas covered by bioenergy_grass and bioenergy_trees from the c4per and c3per classes, respectively. Thereby the area of total and irrigated cropland (including both land for food-feed production and land for bioenergy plantations) provided by the harmonization method is preserved (see Supplement for details of the separation). As needed by many impact models, LUH2-ISIMIP2b also contains a further level of disaggregation of the agricultural land classes c3per, c4per, c3ann, c4ann, and c3nfx into major individual crops (maize, groundnut, rapeseed, soybeans, sunflower, rice, sugarcane, pulses, temperate cereals (incl. wheat), temperate roots, tropical cereals, tropical roots, others annual, others perennial, and others N-fixing) following Monfreda et al. (2008). For all classes we also separate between rainfed and irrigated areas based on the irrigation fraction of total cropland described within HYDE3.2 or projected by MAgPIE (see Supplement).

\section{Patterns of sea-level rise}

Sea-level rise is an important factor for climate-changerelated impacts on coastal infrastructure and ecosystems. For ISIMIP2b we utilize knowledge on the individual components of sea-level rise to provide time-dependent and spatially resolved patterns of sea-level rise. Thermal expansion,

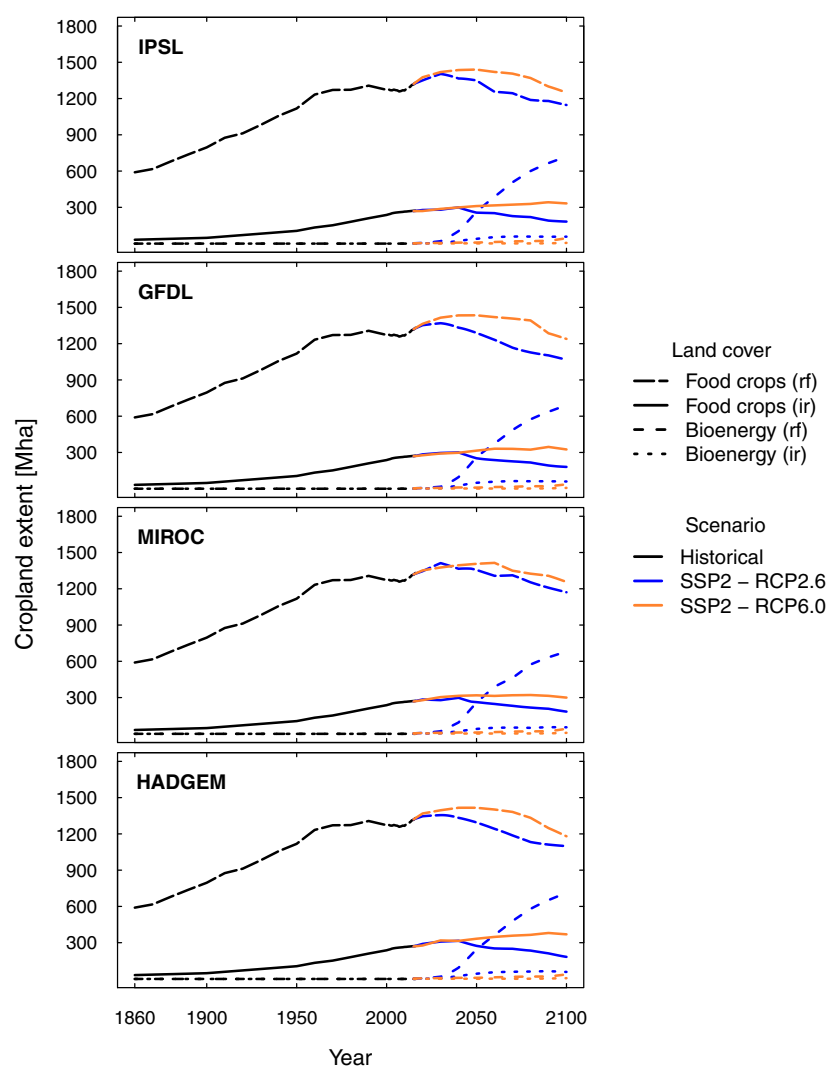

Figure 3. Time series of total cropland for food-feed production (rainfed (long-dashed lines) and irrigated (solid lines)) as reconstructed for the historical period (1860-2015) based on HYDE3.2 (Klein Goldewijk, 2016) and projected under SSP2 (2016-2099), assuming no explicit mitigation of greenhouse gas emissions (RCP6.0, yellow line) and strong mitigation including land-based mitigation (RCP2.6, dark blue line) as suggested by MAgPIE and harmonized according to (Hurtt et al., 2017). Future projections also include rainfed (dashed lines) and irrigated (dotted lines) land areas for bioenergy trees and grasses for the demand generated from the Integrated Assessment Modelling Framework REMIND-MAgPIE in the SSP exercise.

mountain glaciers, and ice caps, as well as the large ice sheets on Greenland and Antarctica are the major climatedependent contributors to sea-level rise. In contrast, land water storage depends predominantly on human activities of groundwater extraction and dam building, with no clear direct relation to climate change on multi-decadal timescales. We construct the pattern of total sea-level rise by the sum of these components, using the pattern of oceanic changes directly from the four GCMs and utilizing fingerprints (Bamber and Riva, 2010) to scale the global glacier and ice sheet contributions. Group 2 and Group 3 experiments differ by the additional land water storage term considered in the sea-level patterns provided for the Group 3 simulations. The associated spatial patterns are also constructed through fingerprinting. While glacier and ice sheet fingerprints are constant in 
time, the spatially resolved changes in land water storage are incorporated in its fingerprint.

We derive the global future sea-level contribution from mountain glaciers and the Greenland and the Antarctic ice sheets with the "constrained extrapolation" approach (Mengel et al., 2016), driven by the global-mean-temperature evolution of the four ISIMIP GCMs. The approach combines information about long-term sea-level change with observed short-term responses and allows the projection of the different contributions to climate-driven sea-level rise from globalmean-temperature change (see Supplement, Figs. S1-S5). We add the contribution from glaciers that is not driven by current climate change (Marzeion et al., 2014). The linear trend of the natural-glacier contribution (Marzeion and Levermann, 2014, Fig. 1c) suggests that the natural contribution reaches zero around year 2056. We therefore approximate this contribution by a parabola with a maximum in 2056, extended with a zero trend beyond that year (see Supplement, black line in Fig. S5). Future total global sea-level rise as the combination of thermal expansion and the glaciers and ice sheets contribution is shown in Fig. 4 (blue and yellow line for RCP2.6 and RCP6.0, respectively).

Global water models can provide projections of future terrestrial water storage (TWS). Reductions in terrestrial water storage influence sea level through adding mass to the ocean and through its gravitational and rotational fingerprint. Within ISIMIP2b we will use TWS projections from the Group 3 simulations by the global water model PCRGLOBWB, accounting for ground water depletion (Wada et al., 2012). Projections will be combined with fingerprinting (Bamber and Riva, 2010) to provide the pattern of sealevel rise from TWS changes for each ISIMIP2b GCM. As Group 3 PCR-GLOBWB experiments are not yet available, TWS changes are not reflected in Fig. 4.

Past global sea-level rise is available through a metaanalysis of proxy relative sea-level reconstructions (Kopp et al., 2016). We match past observed and future projected total sea-level rise by providing both time series relative to the year 2005. We use the observed time series before the year 2005 (Fig. 4, black line) and the projections after that year (Fig. 4, blue (RCP2.6) and yellow (RCP6.0) line). Here, we do not provide patterns of regional sea-level rise for the past. Modellers should use the global mean sea-level rise for simulations of the past (Group 1 historical experiment).

\section{Information about population patterns and economic output (gross domestic product, GDP)}

We provide annual population data on a $0.5^{\circ}$ grid covering the whole period from 1860 to 2100 . The historic data are taken from the HYDE3.2 database (Klein Goldewijk et al., 2011, 2010), which covers the period 1860 to 2000 in 10year time steps plus yearly data between 2001 and 2015 with a default resolution of $5^{\prime}$.

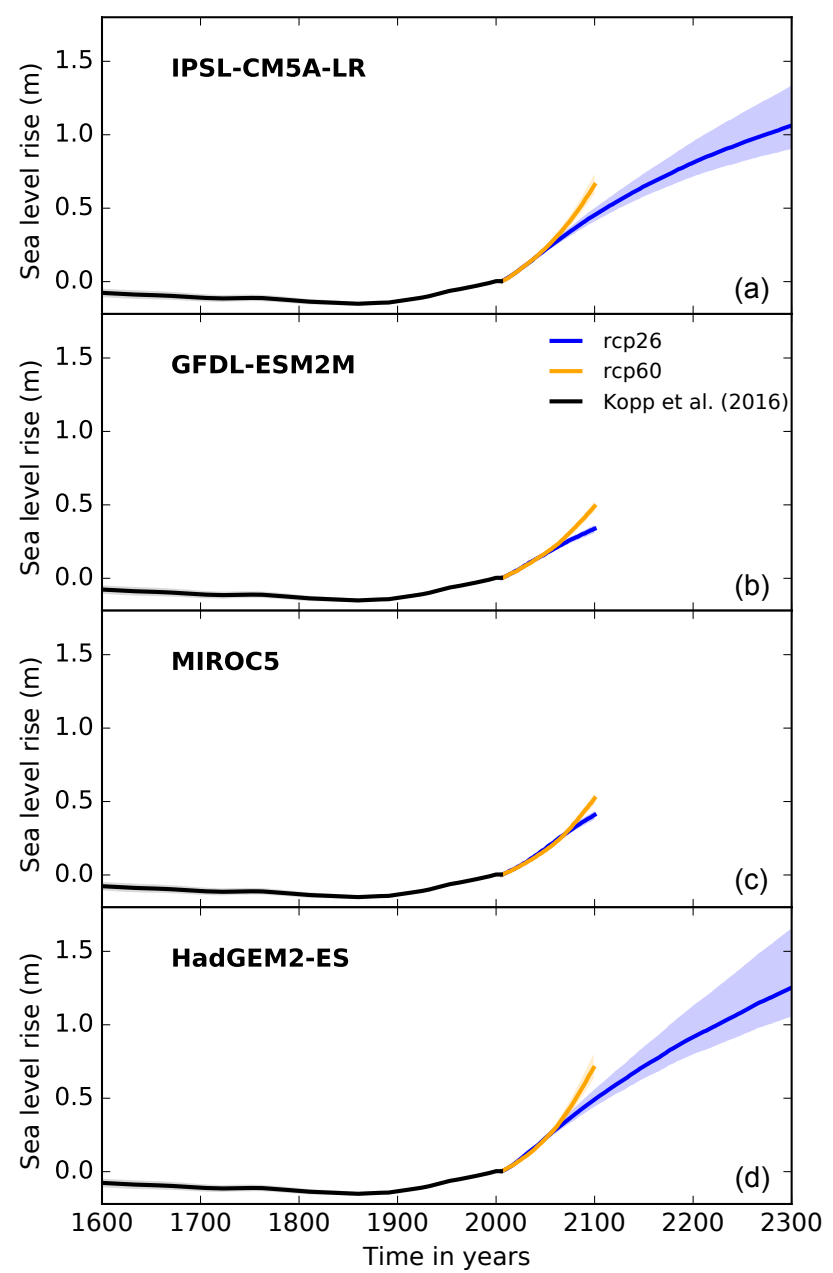

Figure 4. Time series of global total sea-level rise based on observations (Kopp et al., 2016, black line) until year 2005 and global-mean-temperature change from IPSL-CM5A-LR (a), GFDL-ESM2M (b), MIROC5 (c), and HadGEM2-ES (d) after year 2005: solid lines: median projections, shaded areas: uncertainty range between the 5th and 95th percentile of the uncertainty distribution associated with the ice components. Blue: RCP2.6, yellow: RCP6.0. All time series relative to year 2005. Non-climatedriven contribution from glaciers and land water storage are added to the projections.

For the future period, gridded data based on the national SSP2 population projections as described in Samir and Lutz (2014) are available (Jones and O'Neill, 2016) covering the period 2010-2100 in 10-year time steps, with a 7.5' resolution. For ISIMIP2b both datasets are remapped to the ISIMIP $0.5^{\circ}$ grid and interpolated to yearly time steps using a simple linear algorithm. From 2005 onwards, historical population data is linearly interpolated to match with 2010 SSP2 population projections. In addition, we provide age-specific population data (in 5-year age groups: 0-4, 5-9, etc.) and allage mortality rates in 5-year time steps on a country level for 2010-2100, corresponding to the same SSP2 projections by 


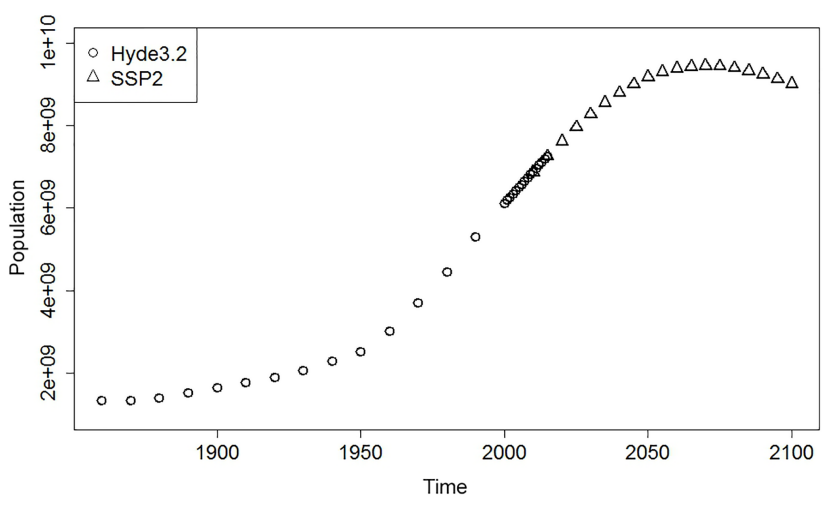

Figure 5. Time series of global population for the historical period (dots) and future projections following the SSP2 storyline (triangles).

Samir and Lutz (2014). Figure 5 shows total global population over time. Both datasets take into account urbanization trends.

Furthermore, annual country-level GDP data (in 2005 USD PPP) are provided (Geiger, 2017, see Fig. 6). The historical data (1860-2010) are derived by extrapolating national income (GDP per capita) and GDP time series (2005 USD PPP) between 1960-2009 from Penn World Tables 8.1 (Feenstra et al., 2015, www.ggdc.net/pwt) with per capita growth rates from the Maddison project (Bolt and van Zanden, 2014, www.ggdc.net/maddison/maddison-project/ home.htm). Missing country data is filled using data first from Penn World Tables 9.0 (Feenstra et al., 2015) and then World Development Indicators (http://data.worldbank. org/) upon required transformation from 2011 USD PPP to 2005 USD PPP (Geiger, 2017).

Future projections of national GDP are taken from the SSP database (Dellink et al., 2015, https://secure.iiasa.ac.at/ web-apps/ene/SspDb/).The database includes country-level GDP projections from 2010-2100 in 10-year time steps that are linearly interpolated to provide annual coverage. From 2005 onwards, historical national GDP data are linearly interpolated to match with OECD SSP2 GDP projections in 2010.

In addition, consistent gridded $\left(0.5^{\circ} \times 0.5^{\circ}\right)$ GDP data are also provided for the period 1860-2100. For the historical period, the above-mentioned national GDP time series in 10year increments are downscaled to $0.125^{\circ}$ grid resolution based on the methodology described in Murakami and Yamagata (2017) and corresponding gridded population data from the HYDE3.2 database (Klein Goldewijk et al., 2011, 2010). Using linear interpolation routines, the data are upscaled to the ISIMIP $0.5^{\circ}$ grid and interpolated to yearly time steps. For the future period, gridded GDP data were generated similarly, using OECD SSP2 national GDP and SSP2 gridded population projections (Jones and O'Neill, 2016) as input for the downscaling. The GDP data will be addi-

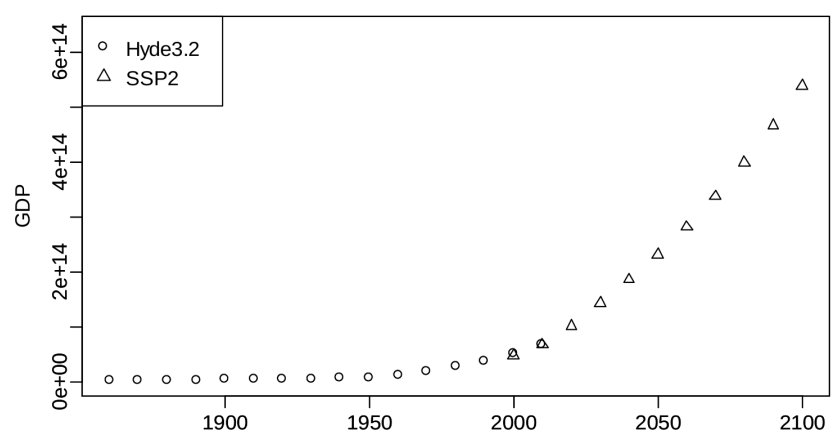

Figure 6. Time series of global GDP for the historical period (dots) and future projections following the SSP2 storyline (triangles).

tionally available from "Global dataset of gridded population and GDP scenarios," which is provided by the Global Carbon Project, National Institute for Environmental Studies (http://www.cger.nies.go.jp/gcp/population-and-gdp.html).

\section{Representation of other external drivers}

There are other drivers that are well documented and partly represented in climate-impact models and also refer to representation of "socio-economic conditions" here. Available indicators apart from climate change, population changes, changes in national GDP, and LU patterns are primarily (1) construction of dams and reservoirs, (2) irrigation-water extraction, (3) patterns of inorganic fertilizer application rates, (4) nitrogen deposition, (5) information about fishing intensities, (6) forest management, and (7) initial conditions for the forestry simulations. For all of these input variables, we describe reconstructions to be used for the historical "histsoc" simulations (see Table 4). For models that do not allow for time-varying socio-economic conditions across the historical period, the conditions should be fixed at presentday (year 2005) levels (see dashed line in Fig. 1, Group 1). Socio-economic conditions beyond 2005 should be held constant (Group 2) or varied according to SSP2 if associated projections are available (Group 3). Within ISIMIP2b we provide projections of future domestic and industrial water withdrawal and consumption, fertilizer application rates, and nitrogen deposition (see Table 4).

\section{Focus regions}

Simulation data are welcome for all world regions. Even single-model simulations for specific sites will help to generate a more comprehensive picture of climate change impacts and potentially allow for constraining global models. However, to allow for model intercomparison, simulations should primarily be provided for the sector-specific focus regions shown in Fig. 7 and defined in Table 5, if feasible with your model. 
Table 4. Representations of socio-economic drivers for the historical simulations (histsoc, Group 1) and the future projections accounting for changes in socio-economic drivers (rcp26soc or rcp60soc, Group 3). * at the beginning of an entry means that it is mandatory to use the dataset(s) provided (if applicable), for reasons of harmonization across models. In other cases, datasets are provided only in support of modelling groups who may need them, but groups are free to use other data or generate the data based on their own simulations following the rules described below.

\begin{tabular}{ll}
\hline Driver & Historical reconstruction \\
\hline $\begin{array}{l}\text { Reservoirs } \\
\text { dams }\end{array}$ & * Includes location, upstream area, capacity, and construction or com- \\
& missioning year, on a global $0.5^{\circ}$ grid. \\
& Documentation: http://www.gwsp.org/products/grand-database.html \\
& (Döll and Lehner, 2002; Lehner et al., 2011). \\
& Note: Simple interpolation can result in inconsistencies between the \\
& GranD database and the DDM30 routing network (wrong upstream \\
& area due to misaligned dam or reservoir location). We provide a file \\
& with locations of all larger dams or reservoirs adapted to DDM30 so \\
& as to best match reported upstream areas.
\end{tabular}

$\begin{array}{ll}\text { Water with- } & \text { Generated by each modelling group individually (e.g. following the } \\ \text { drawal and } & \text { varsoc scenario in ISIMIP2a). For modelling groups that do not have } \\ \text { consumption } & \text { their own representation, we provide files containing the multi-model } \\ \text { for domestic } & \text { mean domestic and industrial water withdrawal and consumption gen- } \\ \& \quad \text { industrial } & \text { erated from the ISIMIP2a varsoc runs of WaterGAP, PCR-GLOBWB, } \\ \text { purposes } & \text { and H08. This data is available from 1901. }\end{array}$

Generated by each modelling group individually.

For modelling groups that do not have their own representation, we provide files containing the multi-model mean (from the global water models WaterGAP, PCRGLOBWB, and H08) domestic and industrial water withdrawal and consumption under SSP2 from the Water Futures and Solutions (WFaS) (Wada et al., 2016) project. Since this data is only available until 2050, the values should be kept constant from 2050 onwards. Also, the data provided for rep26soc and rcp60soc are identical and both are taken from simulations based on RCP6.0. The combination SSP2-RCP2.6 was not considered in $\mathrm{WFaS}$; the difference is expected to be small since the choice of RCP only affects cooling water demand in one of the three models.

Water with- Individually derived by each modelling group from the provided land
drawal (or use and irrigation patterns (see Sect. 4).
consumption)
for irrigation

Individually derived by each modelling group from future land-use and irrigation patterns provided by $\mathrm{MAg}$ PIE (see Sect. 4). Land-use projections are provided for SSP2+RCP6.0, SSP2 + RCP2.6.

\begin{tabular}{|c|c|c|}
\hline $\begin{array}{l}\text { Water with- } \\
\text { drawal (or } \\
\text { consumption) } \\
\text { for livestock } \\
\text { production }\end{array}$ & $\begin{array}{l}\text { Water directly used for livestock (e.g. animal husbandry and drinking) } \\
\text { is expected to be very low (Müller Schmied et al., 2016) and may be } \\
\text { set to zero if not directly represented in the individual models. }\end{array}$ & \\
\hline $\begin{array}{l}\text { Fertilizer (kilo- } \\
\text { gram per hectare } \\
\text { of cropland) }\end{array}$ & $\begin{array}{l}\text { * Annual crop-specific input per hectare of cropland for } \mathrm{C}_{3} \text { and } \mathrm{C}_{4} \\
\text { annual, } \mathrm{C}_{3} \text { and } \mathrm{C}_{4} \text { perennial, and } \mathrm{C}_{3} \text { nitrogen fixing. This dataset is } \\
\text { part of the LUH2 dataset based on HYDE3.2. }\end{array}$ & $\begin{array}{l}\text { * Crop group-specific inorganic } \mathrm{N} \text { fer- } \\
\text { tilizer use per area of cropland pro- } \\
\text { vided by the LUH2-ISIMIP2b dataset, } \\
\text { which differs for SSP2 }+ \text { RCP2.6 and } \\
\text { SSP2 + RCP6.0. }\end{array}$ \\
\hline
\end{tabular}


Table 4. Continued.

\begin{tabular}{|c|c|c|}
\hline Driver & Historical reconstruction & Future projections \\
\hline $\begin{array}{l}\text { Nitrogen depo- } \\
\text { sition }\left(\mathrm{NH}_{x} \text { and }\right. \\
\left.\mathrm{NO}_{y}\right)\end{array}$ & $\begin{array}{l}\text { * Annual, gridded } \mathrm{NH}_{x} \text { and } \mathrm{NO}_{y} \text { deposition during } 1850-2005 \text { de- } \\
\text { rived by averaging three atmospheric chemistry models (i.e. GISS-E2- } \\
\mathrm{R} \text {, CCSM-CAM3.5, and GFDL-AM3) in the Atmospheric Chemistry } \\
\text { and Climate Model Intercomparison Project (ACCMIP) }\left(0.5^{\circ} \times 0.5^{\circ}\right) \\
\text { (Lamarque et al., 2013a, b). The GISS-E2-R provided monthly ni- } \\
\text { trogen deposition output, CCSM-CAM3.5 provided monthly nitrogen } \\
\text { deposition in each decade from } 1850 \text { s to the } 2000 \text { s, and GFDL-AM3 } \\
\text { provided monthly nitrogen deposition in five periods ( } 1850-1860 \text {, } \\
\text { 1871-1950, 1961-1980, 1991-2000, 2001-2010). Annual deposition } \\
\text { rates were calculated by aggregating the monthly data, and nitrogen } \\
\text { deposition rates in years without model output were calculated ac- } \\
\text { cording to spline interpolation (CCSM-CAM3.5) or linear interpola- } \\
\text { tion (for GFDL). The original deposition data was downscaled to spa- } \\
\text { tial resolution of half degree }\left(90^{\circ} \mathrm{N} \text { to } 90^{\circ} \mathrm{S}, 180^{\circ} \mathrm{W} \text { to } 180^{\circ} \mathrm{E}\right) \text { by } \\
\text { applying the nearest interpolation. }\end{array}$ & $\begin{array}{l}\text { * As per historical reconstruction for } \\
\text { 2006-2099 following RCP2.6 and } \\
\text { RCP6.0. }\end{array}$ \\
\hline Fishing intensity & $\begin{array}{l}\text { * Depending on model construction, one of the following: fishing ef- } \\
\text { fort from the Sea Around Us Project (SAUP); catch data from the Re- } \\
\text { gional Fisheries Management Organizations (RFMOs) local fisheries } \\
\text { agencies; exponential fishing technological increase and SAUP eco- } \\
\text { nomic reconstructions. Given that the SAUP historical reconstruction } \\
\text { starts in 1950, fishing effort should be held at a constant } 1950 \text { value } \\
\text { from } 1860-1950 \text {. }\end{array}$ & * Held constant after 2005 (2005soc). \\
\hline $\begin{array}{l}\text { Forest manage- } \\
\text { ment }\end{array}$ & $\begin{array}{l}\text { * Based on observed stem numbers and common management prac- } \\
\text { tices (see Forest Chapter of ISIMIP2b protocol). }\end{array}$ & $\begin{array}{l}* \text { Based on species-specific future man- } \\
\text { agement practices and site specific regen- } \\
\text { eration guidelines (see Forest Chapter of } \\
\text { ISIMIP2b protocol). }\end{array}$ \\
\hline $\begin{array}{l}\text { Forest site, } \\
\text { soil, and stand } \\
\text { description }\end{array}$ & $\begin{array}{l}\text { * Initial site, soil, and stand description of forest stands based on } \\
\text { observed site (elevation, aspect, slope), soil (physical and chemical } \\
\text { soil properties), and stand descriptions (including individual tree data } \\
\text { for diameter at breast height, tree height and species, and stand data } \\
\text { for basal area, age, biomasses of tree compartments, etc.) (see Forest } \\
\text { Chapter of ISIMIP2b protocol for details). }\end{array}$ & $\begin{array}{l}* \text { Unless dynamically simulated, initial } \\
\text { values from site and soil description } \\
\text { should be held constant. }\end{array}$ \\
\hline
\end{tabular}

\section{Implementation of scenario design}

Here, we provide an example of the chosen simulation scenarios consistent with those depicted in Fig. 1 for the global and regional water sector. The grey, red, and blue background colours of the different entries in the tables indicate Group 1, 2 , and 3 runs, respectively. Runs marked in violet represent additional sector-specific sensitivity experiments. Analogous tables for the other sectors are provided in the Supplement while more technical details such as variable names and output formats are provided in a protocol document dedicated to impact modellers intending to participate in ISIMIP2b (www.isimip.org/protocol/\#isimip2b). The scenario table for the lake sector is under development and not yet included in the Supplement, while the list of output variables is already included in the protocol document.

Each simulation run has a name (Experiment I to VII) that is consistent across sectors, i.e. runs from the individual ex- periments could be combined for a consistent cross-sectoral analysis. Since socio-economic conditions represented in individual sectors may depend on the RCPs (such as land-use changes), while socio-economic conditions relevant for other sectors may only depend on the SSP, the number of experiments differs from sector to sector.

For the historical period, groups that have limited computational capacities may choose to report only part of the full period, but should include at least 1961-2005. All other periods should be reported completely. For those models that do not represent changes in socio-economic conditions, those impacts should be held fixed at 2005 levels throughout all Group 1 (see "2005soc" marked as dashed blue lines in Fig. 1) and Group 2 simulations. Group 3 will be identical to Group 2 for these models and thus does not require additional simulations. Models that do not include human impacts at all are asked to run the Group 1 and Group 2 simulations nonetheless, since these simulations will still allow 


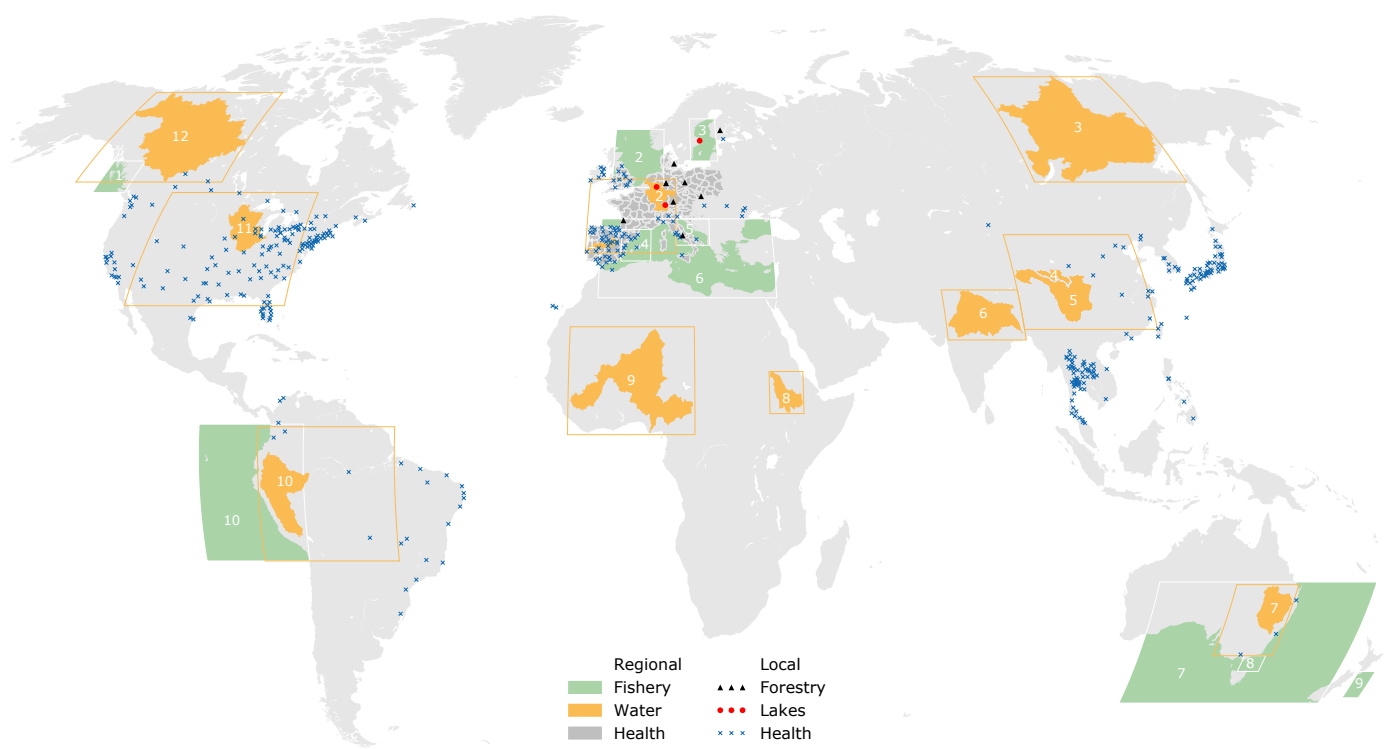

Figure 7. ISIMIP focus regions. The coordinates of the numbered regions are listed in Table 5.

for an exploration of the effects of climate change compared to pre-industrial climate, and will also allow for a better assessment of the relative importance of human impacts versus climate impacts. These runs should be named as "nosoc" simulations.

\section{Model spin-up}

Since the pre-industrial simulations are an important part of the experiments, the spin-up has to be finished before the pre-industrial simulations start. The spin-up should be for the pre-industrial climate (picontrol) and year 1860 socioeconomic conditions. For this reason, the pre-industrial climate data should be replicated by each modelling group as often as required. The precise implementation of the spin up will be model specific, the description of which will be part of the reporting process.

\section{Intended time line of simulations}

The time line of ISIMIP2b has been chosen to meet the critical deadlines of the drafting process of the IPCC Special Report, with the submission deadline for papers to be considered in the Special Report being 1 November 2017 and the associated acceptance deadline being in 15 May 2018. A range of ISIMIP2b impact simulations have been submitted in time and are available via https://esg.pik-potsdam.de/ projects/isimip2b/. Except for the oceanic data, all input data for the Group 1 and 2 simulations are available. The processing of the LU patterns will soon be finalized to allow for starting the Group 3 simulations. The ISIMIP2b repository will stay open for impact simulations submitted beyond October 2017, since the described simulations provide a basis for further research beyond the direct demands of the Special Report, including for the IPCC Sixth Assessment Report.

\section{Discussion}

Our protocol addresses a timely and important research gap that we have identified for developing a framework for assessing the impacts of 1.5 and $2{ }^{\circ} \mathrm{C}$ global warming on a multitude of different impact sectors. Whilst a number of studies have investigated the impacts of 1.5 and $2{ }^{\circ} \mathrm{C}$ on individual impact sectors (Arnell et al., 2014; Gosling et al., 2016; Roudier et al., 2015), our approach provides a novel extension to these by (1) incorporating multiple GCMs, impact models, and sectors, (2) inclusion of a pre-industrial reference and full coverage of the historical period, (3) providing a consistent and documented framework for the assessment of impacts at the global scale, and (4) seeking to achieve multi-model integration between sectors in order to better represent the links and feedbacks that occur in the observed Earth system.

The last item above, in particular, is a significant step change in how climate-change-impact modelling is conducted, since up until now the assessment of global-scale climate-sensitive impacts for different sectors have typically been conducted in isolation from one another, e.g. the watersector models do not use LU changes from the biome-sector models, and in turn the crop-sector models do not use runoff from the water-sector models, etc. Running impact models in isolation from one another can ignore complex interdependencies which in turn can be detrimental to the representation of spatial patterns in climate change impacts, as well as their sign and magnitude of change (Harrison et al., 2016). En- 
Table 5. List of ISIMIP focus regions as shown in Fig. 7.

\begin{tabular}{|c|c|c|c|}
\hline $\begin{array}{l}\text { Focus region (short name) } \\
\text { Numbers refer to regions as shown in the } \\
\text { map in Fig. } 7 .\end{array}$ & $\begin{array}{l}\text { Zonal extent } \\
\text { (longitude) }\end{array}$ & $\begin{array}{l}\text { Meridional extent } \\
\text { (latitude) }\end{array}$ & $\begin{array}{l}\text { River basin(s) or } \\
\text { Region (short name) }\end{array}$ \\
\hline \multicolumn{4}{|l|}{ Regional water simulations } \\
\hline North America (11) (nam) & $114^{\circ} 0^{\prime} \mathrm{W}-77^{\circ} 30^{\prime} \mathrm{W}$ & $28^{\circ} 30^{\prime} \mathrm{N}-50^{\circ} 0^{\prime} \mathrm{N}$ & Mississippi (mississippi) \\
\hline Western Europe $(1,2)$ (weu) & $9^{\circ} 30^{\prime} \mathrm{W}-12^{\circ} 0^{\prime} \mathrm{E}$ & $38^{\circ} 30^{\prime} \mathrm{N}-52^{\circ} 30^{\prime} \mathrm{N}$ & Tagus und Rhine (rhine) \\
\hline West Africa (9) (waf) & $12^{\circ} 0^{\prime} \mathrm{W}-16^{\circ} 0^{\prime} \mathrm{E}$ & $4^{\circ} 0^{\prime} \mathrm{N}-24^{\circ} 30^{\prime} \mathrm{N}$ & Niger (niger) \\
\hline South Asia (6) (sas) & $73^{\circ} 0^{\prime} \mathrm{E}-90^{\circ} 30^{\prime} \mathrm{E}$ & $22^{\circ} 0^{\prime} \mathrm{N}-31^{\circ} 30^{\prime} \mathrm{N}$ & Ganges (ganges) \\
\hline China $(4,5)(\mathrm{chi})$ & $90^{\circ} 30^{\prime} \mathrm{E}-120^{\circ} 30^{\prime} \mathrm{E}$ & $24^{\circ} 0^{\prime} \mathrm{N}-42^{\circ} 0^{\prime} \mathrm{N}$ & $\begin{array}{l}\text { Yellow (yellow), Yangtze (yangtze) } \\
\text { (yellow,gtze) }\end{array}$ \\
\hline Australia (7) (aus) & $138^{\circ} 30^{\prime} \mathrm{E}-152^{\circ} 30^{\prime} \mathrm{E}$ & $38^{\circ} 0^{\prime} \mathrm{S}-24^{\circ} 30^{\prime} \mathrm{S}$ & Murray Darling (murrydarling) \\
\hline Amazon (10) (ama) & $80^{\circ} 0^{\prime} \mathrm{W}-50^{\circ} 0^{\prime} \mathrm{W}$ & $20^{\circ} 0^{\prime} \mathrm{S}-5^{\circ} 30^{\prime} \mathrm{N}$ & Amazon (amazon) \\
\hline Blue Nile (8) (blu) & $32^{\circ} 30^{\prime} \mathrm{E}-40^{\circ} 0^{\prime} \mathrm{E}$ & $8^{\circ} 0^{\prime} \mathrm{N}-16^{\circ} 0^{\prime} \mathrm{N}$ & Blue Nile (bluenile) \\
\hline Lena (3) (len) & $103^{\circ} 0^{\prime} \mathrm{E}-141^{\circ} 30^{\prime} \mathrm{E}$ & $52^{\circ} 0^{\prime} \mathrm{N}-72^{\circ} 0^{\prime} \mathrm{N}$ & Lena (lena) \\
\hline Canada (12) (can) & $140^{\circ} 0^{\prime} \mathrm{W}-103^{\circ} 0^{\prime} \mathrm{W}$ & $52^{\circ} 0^{\prime} \mathrm{N}-69^{\circ} 0^{\prime} \mathrm{N}$ & Mackenzie (mackenzie) \\
\hline \multicolumn{4}{|l|}{ Regional lake simulations } \\
\hline Große Dhünn (reservoir) & $7^{\circ} 12^{\prime} \mathrm{E}$ & $51^{\circ} 04^{\prime} \mathrm{N}$ & \\
\hline Lake Constance (Bodensee) & $9^{\circ} 24^{\prime} \mathrm{E}$ & $47^{\circ} 37^{\prime} \mathrm{N}$ & \\
\hline Lake Erken & $18^{\circ} 35^{\prime} \mathrm{E}$ & $59^{\circ} 51^{\prime} \mathrm{N}$ & \\
\hline \multicolumn{4}{|l|}{ Regional forestry simulations } \\
\hline BilyKriz & 18.32 & 49.300 & - \\
\hline Collelongo & 13.588 & 41.849 & \\
\hline Soro & 11.645 & 55.486 & \\
\hline Hyytiala & 24.295 & 61.848 & \\
\hline Kroof & 11.400 & 48.250 & \\
\hline Solling 304 & 9.570 & 51.770 & \\
\hline Solling 305 & 9.570 & 51.770 & \\
\hline Peitz & 14.350 & 51.917 & \\
\hline LeBray & -0.769 & 44.717 & \\
\hline \multicolumn{4}{|l|}{ Ocean regions } \\
\hline North-west Pacific (1) (pacific-nw) & $134^{\circ} 30^{\prime} \mathrm{W}-125^{\circ} 30^{\prime} \mathrm{W}$ & $49^{\circ} 30^{\prime} \mathrm{N}-56^{\circ} 30^{\prime} \mathrm{N}$ & \\
\hline North Sea (2) (north-sea) & $4^{\circ} 30^{\prime} \mathrm{W}-9^{\circ} 30^{\prime} \mathrm{E}$ & $50^{\circ} 30^{\prime} \mathrm{N}-62^{\circ} 30^{\prime} \mathrm{N}$ & \\
\hline Baltic Sea (3) & $15^{\circ} 30^{\prime} \mathrm{E}-23^{\circ} 30^{\prime} \mathrm{E}$ & $55^{\circ} 30^{\prime} \mathrm{N}-64^{\circ} 30^{\prime} \mathrm{N}$ & \\
\hline North-west Mediterranean (4) (med-nw) & $1^{\circ} 30^{\prime} \mathrm{W}-6^{\circ} 30^{\prime} \mathrm{E}$ & $36^{\circ} 30^{\prime} \mathrm{N}-43^{\circ} 30^{\prime} \mathrm{N}$ & \\
\hline Adriatic Sea (5) (adriatic-sea) & $11^{\circ} 30^{\prime} \mathrm{E}-20^{\circ} 30^{\prime} \mathrm{E}$ & $39^{\circ} 30^{\prime} \mathrm{N}-45^{\circ} 30^{\prime} \mathrm{N}$ & \\
\hline Meditteranean Sea (6) (med-glob) & $6^{\circ} 30^{\prime} \mathrm{W}-35^{\circ} 30^{\prime} \mathrm{E}$ & $29^{\circ} 30^{\prime} \mathrm{N}-45^{\circ} 30^{\prime} \mathrm{N}$ & \\
\hline Australia (7) (australia) & $120^{\circ} 30^{\prime} \mathrm{E}-170^{\circ} 30^{\prime} \mathrm{E}$ & $47^{\circ} 30^{\prime} \mathrm{S}-23^{\circ} 30^{\prime} \mathrm{S}$ & \\
\hline $\begin{array}{l}\text { Eastern Bass Strait (8) (eastern-bass- } \\
\text { strait) }\end{array}$ & $145^{\circ} 30^{\prime} \mathrm{E}-151^{\circ} 30^{\prime} \mathrm{E}$ & $41^{\circ} 30^{\prime} \mathrm{S}-37^{\circ} 30^{\prime} \mathrm{S}$ & \\
\hline Cook Strait (9) (cook-strait) & $174^{\circ} 30^{\prime} \mathrm{E}-179^{\circ} 30^{\prime} \mathrm{E}$ & $46^{\circ} 30^{\prime} \mathrm{S}-40^{\circ} 30^{\prime} \mathrm{S}$ & \\
\hline North Humboldt Sea (14) (humboldt-n) & $93^{\circ} 30^{\prime} \mathrm{W}-69^{\circ} 30^{\prime} \mathrm{W}$ & $20^{\circ} 30^{\prime} \mathrm{S}-6^{\circ} 30^{\prime} \mathrm{N}$ & \\
\hline
\end{tabular}

hancing cross-sectoral integration has been one of the driving forces behind the development of the ISIMIP2b protocol, so we anticipate that the simulations which arise from it will yield some of the most cutting-edge projections of climate change impacts to date.

As well as facilitating an understanding of the impacts of 1.5 and $2{ }^{\circ} \mathrm{C}$ warming, the ISIMIP2b scenario design also enables an assessment of the impacts of the $1^{\circ} \mathrm{C}$ of global warming that has occurred between pre-industrial times and the present day. There are surprisingly few studies that have investigated this, in part due to the significant resources needed to conduct the lengthy climate and impact simulations that are required. To understand what effect anthropogenic climate change has had since pre-industrial times requires an understanding of the climate-change conditions that would prevail in the present day in the absence of anthropogenic greenhouse gas emissions as well as an estimate of how climate-sensitive impacts have responded to 
Table 6. Scenario description.

\begin{tabular}{|c|c|}
\hline \multicolumn{2}{|c|}{ Climate $\& \mathrm{CO}_{2}$ concentration scenarios } \\
\hline picontrol & $\begin{array}{l}\text { Pre-industrial climate and } 286 \mathrm{ppm} \mathrm{CO} \mathrm{CO}_{2} \text { concentration. The provided input data cover entire period (1661- } \\
2299) \text { partly based on a recycling of data. The order of years should not be changed. }\end{array}$ \\
\hline historical & Historical climate and $\mathrm{CO}_{2}$ concentration. \\
\hline rcp26 & Future climate and $\mathrm{CO}_{2}$ concentration from $\mathrm{RCP} 2.6$. \\
\hline rcp60 & Future climate and $\mathrm{CO}_{2}$ concentration from RCP6.0. \\
\hline $2005 \operatorname{co} 2$ & $\mathrm{CO}_{2}$ concentration fixed at 2005 levels (378.81 ppm). Used in the biomes and forestry sector. \\
\hline 2299rcp26 & $\begin{array}{l}\text { Repeating climate between } 2270 \text { and } 2299 \text { for additional } 200 \text { years up to } 2500 \text { (or equilibrium if possible), } \\
\mathrm{CO}_{2} \text { fixed at year } 2299 \text { levels. Used in the permafrost sector. }\end{array}$ \\
\hline \multicolumn{2}{|c|}{$\begin{array}{l}\text { Representation of socio-economic conditions } \\
\text { Refers to land use and other (human) influences including nitrogen deposition, fertilizer input, irrigation, water } \\
\text { abstraction, dams and reservoirs, forest management, mortality baselines, exposure-response functions } \\
\text { (temperature-related mortality), population and GDP data, coastal protection, and fishing catch data. }\end{array}$} \\
\hline 1860soc & Pre-industrial land use and socio-economic conditions. \\
\hline & Varying historical land use and socio-economic conditions. \\
\hline 2005soc & $\begin{array}{l}\text { Fixed year- } 2005 \text { land use and socio-economic conditions. In the regional forest sector the scenario means } \\
\text { managing future forests according to present-day management guidelines without species change and keep- } \\
\text { ing the same rotation length and thinning types. }\end{array}$ \\
\hline 2015 soc & $\begin{array}{l}\text { Fixed year-2005 land use and socio-economic conditions. The scenario is only considered in the energy } \\
\text { sector where } 2015 \text { conditions are already dramatically different from } 2005 \text { conditions. }\end{array}$ \\
\hline rcp26soc & $\begin{array}{l}\text { Varying land use and socio-economic conditions according to SSP2 and RCP2.6. In the regional forest sector } \\
\text { future forests are assumed to be managed by changing the tree species and the forest management towards } \\
\text { maximizing mitigation benefits. Depending on the region and forest stand, this could mean focusing on } \\
\text { species and management measures to maximize (1) the production of wood for bioenergy (highly productive } \\
\text { species, short rotations), (2) in situ carbon stocks, or (3) production of harvested wood products with a long } \\
\text { lifetime. }\end{array}$ \\
\hline rcp60soc & $\begin{array}{l}\text { Varying land use and socio-economic conditions according to SSP2 and RCP6.0. In the regional forest sector } \\
\text { future forest are assumed to require adaptive management such as "assisted migration" where present-day } \\
\text { forests are managed according to current practices until final harvest and then replaced by tree species that } \\
\text { would be the natural vegetation under the projected climate change according to Hanewinkel et al. (2012). }\end{array}$ \\
\hline 2100rcp26soc & $\begin{array}{l}\text { Land use and socio-economic conditions fixed at year } 2100 \text { levels according to the final year of RCP2.6. In } \\
\text { the regional forest sector the scenario means managing future forests according to rcp } 26 \text { soc guidelines. }\end{array}$ \\
\hline $2100 \mathrm{ssp} 2 \mathrm{soc}$ & $\begin{array}{l}\text { This scenario is considered, for example, in the health sector where socioeconomic conditions after } 2100 \text { are } \\
\text { fixed at } 2100 \text { levels of SSP2. In this case the socio-economic changes are not assumed to depend on climate. }\end{array}$ \\
\hline ssp2soc_adapt & Varying society according to SSP2 - with adaptation (temperature-related mortality simulations). \\
\hline nosoc & No human influences (permafrost, regional forest, and fisheries simulations). \\
\hline
\end{tabular}

human-induced LU change and land management since preindustrial times.

To disentangle the magnitude of climate-sensitive impacts from changes in these impacts that have occurred due to other human activities, the scenario design compares a simulation where human influences on climate-sensitive impacts occur under a pre-industrial climate, driven by stable greenhouse gas concentrations, with another simulation for the same time period, where the climate responds to increases in greenhouse gas emissions, and where there are direct (human) influences on climate-sensitive indicators. It seems intuitive that the difference between these two simulations will yield the pure effect of climate change, whilst controlling for the other drivers. However, we acknowledge that in practical terms, the effects of human activity on the climate and climate-sensitive impacts are intrinsically linked and cannot be separated precisely. For example, whilst we are able to use historical estimates of water abstractions and dam construction as one of the human influences in both of the above simulations, a proportion of the abstractions and construction of dams will have occurred at the time in response to climate variability and based on decisions related to planning for future climate change. Such a caveat has to be accepted within the context of a numerical modelling framework such as ours.

However, the explicit representation of socio-economic drivers on impact indicators means an important step forward compared to the ISIMIP Fast Track simulations. In particular, the assessment of potential trade-offs of specific mitigation measures such as expansion of bioenergy production will become critical when implementing the Paris agreement of limiting global warming to "well below $2{ }^{\circ} \mathrm{C}$ ". 
Table 7. ISIMIP2b scenario specification example for the global and regional water model simulations. Option $2 *$ only if option 1 not possible.

\begin{tabular}{|c|c|c|c|c|c|c|}
\hline & Experiment & Input & $\begin{array}{l}\text { Pre-industrial } \\
1661-1860\end{array}$ & $\begin{array}{l}\text { Historical } \\
1861-2005\end{array}$ & $\begin{array}{l}\text { Future } \\
2006-2100\end{array}$ & $\begin{array}{l}\text { Extended future } \\
\text { 2101-2299 }\end{array}$ \\
\hline \multirow[t]{3}{*}{ I } & $\begin{array}{l}\text { no climate change, pre- } \\
\text { industrial } \mathrm{CO}_{2}\end{array}$ & Climate \& $\mathrm{CO}_{2}$ & picontrol & picontrol & picontrol & picontrol \\
\hline & $\begin{array}{l}\text { varying LU \& human influ- } \\
\text { ences up to } 2005 \text {, then fixed } \\
\text { at } 2005 \text { levels thereafter }\end{array}$ & Human \& LU & Option 1: 1860soc & Option 1: histsoc & $2005 \mathrm{soc}$ & $2005 \mathrm{soc}$ \\
\hline & $\begin{array}{l}\text { LU \& human influences } \\
\text { fixed at } 2005 \text { levels }\end{array}$ & & Option $2 *: 2005 \mathrm{soc}$ & Option $2 *: 2005$ soc & & \\
\hline \multirow[t]{3}{*}{ II } & $\mathrm{RCP} 2.6$ climate \& $\mathrm{CO}_{2}$ & Climate \& $\mathrm{CO}_{2}$ & \multirow[t]{3}{*}{ Experiment I } & historical & rcp26 & rcp26 \\
\hline & $\begin{array}{l}\text { varying LU \& human influ- } \\
\text { ences up to } 2005 \text {, then fixed } \\
\text { at } 2005 \text { levels thereafter }\end{array}$ & Human \& LU & & Option 1: histsoc & $2005 \mathrm{soc}$ & $2005 \mathrm{soc}$ \\
\hline & $\begin{array}{l}\text { LU \& human influences } \\
\text { fixed at } 2005 \text { levels }\end{array}$ & & & Option $2 *: 2005$ soc & & \\
\hline \multirow[t]{2}{*}{ III } & RCP6.0 climate \& $\mathrm{CO}_{2}$ & Climate \& $\mathrm{CO}_{2}$ & \multirow[t]{2}{*}{ Experiment I } & \multirow[t]{2}{*}{ Experiment II } & rcp60 & \multirow[t]{2}{*}{ not simulated } \\
\hline & $\begin{array}{l}\text { LU \& human influences } \\
\text { fixed at } 2005 \text { levels after } \\
2005\end{array}$ & Human \& LU & & & $2005 \mathrm{soc}$ & \\
\hline \multirow[t]{2}{*}{ IV } & $\begin{array}{l}\text { no climate change, pre- } \\
\text { industrial } \mathrm{CO}_{2}\end{array}$ & Climate \& $\mathrm{CO}_{2}$ & \multirow[t]{2}{*}{ Experiment I } & \multirow[t]{2}{*}{ Experiment I } & picontrol & picontrol \\
\hline & $\begin{array}{l}\text { varying human influences } \\
\& \text { LU up to } 2100 \text { (RCP2.6), } \\
\text { then fixed at } 2100 \text { levels } \\
\text { thereafter }\end{array}$ & Human \& LU & & & rep26soc & 2100rcp26soc \\
\hline \multirow[t]{2}{*}{$\mathrm{V}$} & $\begin{array}{l}\text { no climate change, pre- } \\
\text { industrial } \mathrm{CO}_{2}\end{array}$ & Climate $\& \mathrm{CO}_{2}$ & \multirow[t]{2}{*}{ Experiment I } & \multirow[t]{2}{*}{ Experiment I } & picontrol & \multirow[t]{2}{*}{ not simulated } \\
\hline & $\begin{array}{l}\text { varying human influences } \\
\text { \& LU (RCP6.0) }\end{array}$ & Human \& LU & & & rcp60soc & \\
\hline \multirow[t]{2}{*}{ VI } & RCP2.6 climate \& $\mathrm{CO}_{2}$ & Climate $\& \mathrm{CO}_{2}$ & \multirow[t]{2}{*}{ Experiment I } & \multirow[t]{2}{*}{ Experiment II } & rcp26 & rcp26 \\
\hline & $\begin{array}{l}\text { varying human influences } \\
\& \text { LU up to } 2100 \text { (RCP2.6), } \\
\text { then fixed at } 2100 \text { levels } \\
\text { thereafter }\end{array}$ & Human \& LU & & & rcp26soc & $2100 \mathrm{rcp} 26 \mathrm{soc}$ \\
\hline \multirow[t]{2}{*}{ VII } & RCP6.0 climate \& $\mathrm{CO}_{2}$ & Climate \& $\mathrm{CO}_{2}$ & \multirow[t]{2}{*}{ Experiment I } & \multirow[t]{2}{*}{ Experiment II } & rcp60 & \multirow[t]{2}{*}{ not simulated } \\
\hline & $\begin{array}{l}\text { varying human influences } \\
\text { \& LU (RCP6.0) }\end{array}$ & Human \& LU & & & rcp60soc & \\
\hline
\end{tabular}

Code and data availability. All input data described in Sects. 3 to 7 will be made publicly available. Availability is documented on www.isimip.org where the way of accessing the data will also be described. Model output is already partly available via https://esg. pik-potsdam.de. Access to the hurricane projections can be gained by request viainfo@windrisktech.com.
The Supplement related to this article is available online at https://doi.org/10.5194/gmd-10-4321-2017supplement.

Competing interests. The authors declare that they have no conflict of interest. 
Acknowledgements. We thank Graham Weedon (Met Office) and Emanuel Dutra (ECMWF), who helped a lot to put together the EWEMBI dataset. COST Action FP1304 for supporting biomes meeting. This research was supported by German Federal Ministry of Education and Research (BMBF, grant no. 01LS1201A2) and in part by the EU FP7 HELIX project (grant no. 603864). Some authors acknowledge funding from the European Union's Horizon 2020 research and innovation programme under grant agreement no. 641816 (CRESCENDO). Some authors acknowledge support from the Leibniz Competition project SAW-2013-PIK-5 (EXPACT). Some authors acknowledge and appreciate funding by the Federal Ministry for the Environment, Nature Conservation, Building and Nuclear Safety 11_II_093_Global_A_SIDS_and_LDCs (SURVIVE). Authors acknowledge funding from the European Union's Horizon 2020 research and innovation programme under grant agreement no. 641816 (CRESCENDO). Met Office authors were supported by the joint UK BEIS-Defra Met Office Hadley Centre Climate Programme (GA01101). Jochen Hinkel has received funding from the European Union's Seventh Programme for Research, Technological Development and Demonstration under grant agreement no. 603396 (RISES-AM project) and from the European Union's Horizon 2020 research and innovation programme under grant agreement no. 642018 (GREEN-WIN project). Derek Tittensor acknowledges funding from the Kanne Rassmussen Foundation, Denmark. The work of Kate Halladay, Eleanor Burke, Richard A. Betts and Chris D. Jones forms part of the BEISDefra Met Office Hadley Centre Climate Programme GA01101. Philippe Ciais acknowledges support from the European Research Council Synergy grant ERC-2013-SyG-610028 IMBALANCE-P and the ANR Convergence Lab project CLAND. Tyler Eddy acknowledges funding from the Nippon Foundation to the Nereus Program. Hanqin Tian acknowledges funding from US National Science Foundation (1243232), National Key Research and Development Program of China (no. 2017YFA0604700), SKLURE Grant (SKLURE2017-1-6).

Tatsuo Suzuki acknowledges funding from the Program for Risk Information on Climate Change by the Japanese Ministry of Education, Sports, Science and Technology. The project has received funding from the European Union's Horizon 2020 research and innovation programme under grant agreements no. 689150 (SIM4NEXUS) and no. 642147 (CD-LINKS).

Riccardo E. M. Riva acknowledges funding from the Netherlands Organization for Scientific Research VIDI grant 864.12.012.

Edited by: Didier Roche

Reviewed by: Albertus J. Dolman and Daniela Jacob

\section{References}

Arnell, N. W., Brown, S., Gosling, S. N., Hinkel, J., Huntingford, C., Lloyd-Hughes, B., Lowe, J. A., Osborn, T., Nicholls, R. J., and Zelazowski, P.: Global-scale climate impact functions: the relationship between climate forcing and impact, Clim. Change, 134, 475-487, 2014.

Balsamo, G., Albergel, C., Beljaars, A., Boussetta, S., Brun, E., Cloke, H., Dee, D., Dutra, E., Muñoz-Sabater, J., Pappenberger, F., de Rosnay, P., Stockdale, T., and Vitart, F.: ERAInterim/Land: a global land surface reanalysis data set, Hydrol.
Earth Syst. Sci., 19, 389-407, https://doi.org/10.5194/hess-19389-2015, 2015.

Bamber, J. and Riva, R.: The sea level fingerprint of recent ice mass fluxes, The Cryosphere, 4, 621-627, https://doi.org/10.5194/tc4-621-2010, 2010.

Bellenger, H., Guilyardi, E., Leloup, J., Lengaigne, M., and Vialard, J.: ENSO representation in climate models: from CMIP3 to CMIP5, Clim. Dynam., 42, 1999-2018, https://doi.org/10.1007/s00382-013-1783-z, 2014.

Bodirsky, B. L., Rolinski, S., Biewald, A., Weindl, I., Popp, A., and Lotze-Campen, H.: Food Demand Projections for the 21st Century, PLoS One, 10, e0139201, https://doi.org/10.1371/journal.pone.0139201, 2015.

Bolt, J. and van Zanden, J. L.: The Maddison Project: collaborative research on historical national accounts, Econ. Hist. Rev., 67, 627-651, 2014.

Bondeau, A., Smith, P. C., Zaehle, S., Schaphoff, S., Lucht, W., Cramer, W., Gerten, D., Lotze-Campen, H., Müller, C., Reichstein, M., and Smith, B.: Modelling the role of agriculture for the 20th century global terrestrial carbon balance, Glob Change Biol., 13, 679-706, 2007.

Buck, A. L.: New Equations for Computing Vapor Pressure and Enhancement Factor, J. Appl. Meteorol., 20, 1527-1532, 1981.

Burke, M., Hsiang, S. M., and Miguel, E.: Global non-linear effect of temperature on economic production, Nature, 527, 235-239, https://doi.org/10.1038/nature15725, 2015.

Christensen, J. H., Kumar, K. K., Aldrian, E., An, S.-I., Cavalcanti, I. F. A., Castro, M. de, Dong, W., Goswami, P., Hall, A., Kanyanga, J. K., Kitoh, A., Kossin, J., Lau, N.-C., Renwick, J., Stephenson, D. B., Xie, S.-P., and Zho, T.: Climate phenomena and their relevance for future regional climate change, in: Climate Change 2013: The physical science basis. Contribution of Working Group I to the fifth Assessment of the Intergovernmental Panel on Climate Change. Cambridge, Ca, Fifth Assessment Report of the Intergovernmental Panel on Climate Change, edited by: Stocker, T. F., Qin, D., Plattner, G.-K., Tignor, M., Allen, S. K., Boschung, J., Nauels, A., Xia, Y., Bex, V., and Midgley, P. M., Cambridge University Press, Cambridge, United Kingdom and New York, NY, USA, 2013.

Coumou, D., Petoukhov, V., Rahmstorf, S., Petri, S., and Schellnhuber, H. J.: Quasi-resonant circulation regimes and hemispheric synchronization of extreme weather in boreal summer, P. Natl. Acad. Sci. USA, 111, 12331-12336, https://doi.org/10.1073/pnas.1412797111, 2014.

Cramer, W., Yohe, G. W., Auffhammer, M., Huggel, C., Molau, U., Dias, M. A. F. da S., Solow, A., Stone, D. A., and Tibig, L.: Detection and attribution of observed impacts, in: Climate Change 2014: Impacts, Adaptation, and Vulnerability. Part A: Global and Sectoral Aspects. Contribution of Working Group II to the Fifth Assessment Report of the Intergovernmental Panel on Climate Change, edited by: Field, C. B., Barros, V. R., Dokken, D. J., Mach, K. J., Mastrandrea, M. D., Bilir, T. E., Chatterjee, M., Ebi, K. L., Estrada, Y. O., Genova, R. C., Girma, B., Kissel, E. S., Levy, A. N., MacCracken, S., Mastrandrea, P. R., and White, L. L., 979-1037, Cambridge University Press, Cambridge, United Kingdom and New York, NY, USA., 2014.

Dee, D. P., Uppala, S. M., Simmons, A. J., Berrisford, P., Poli, P., Kobayashi, S., Andrae, U., Balmaseda, M. A., Balsamo, G., Bauer, P., Bechtold, P., Beljaars, A. C. M., van de Berg, L., Bid- 
lot, J., Bormann, N., Delsol, C., Dragani, R., Fuentes, M., Geer, A. J., Haimberger, L., Healy, S. B., Hersbach, H., Hólm, E. V., Isaksen, L., Kållberg, P., Köhler, M., Matricardi, M., McNally, A. P., Monge-Sanz, B. M., Morcrette, J.-J., Park, B.-K., Peubey, C., de Rosnay, P., Tavolato, C., Thépaut, J.-N., and Vitart, F.: The ERA-Interim reanalysis: configuration and performance of the data assimilation system, Q. J. Roy. Meteorol. Soc., 137, 553597, https://doi.org/10.1002/qj.828, 2011.

Dell, M., Jones, B. F., and Olken, B. A.: Temperature Shocks and Economic Growth: Evidence from the Last Half Century, Am. Econ. J. Macroecon., 4, 66-95, https://doi.org/10.1257/mac.4.3.66, 2012.

Dellink, R., Chateau, J., Lanzi, E., and Magné, B.: Long-term economic growth projections in the Shared Socioeconomic Pathways, Glob. Environ. Chang., https://doi.org/10.1016/j.gloenvcha.2015.06.004, 2015.

Döll, P. and Lehner, B.: Validation of a new global 30min drainage direction map, J. Hydrol., 258, 214-231, https://doi.org/10.1016/S0022-1694(01)00565-0, 2002.

Dutra, E.: Report on the current state-of-the-art Water Resources Reanalysis, Earth2observe deliverable no. D.5.1, available at: http://earth2observe.eu/files/PublicDeliverables (last access: July 2016), 2015.

Emanuel, K., DesAutels, C., Holloway, C., and Korty, R.: Environmental control of tropical cyclone intensity, J. Atmos. Sci., 61, 843-858, 2004.

Emanuel, K., Sundararajan, R., and Williams, J.: Hurricanes and global warming: Results from downscaling IPCC AR4 simulations, B. Am. Meteorol. Soc., 89, 347-367, https://doi.org/10.1175/BAMS-89-3-347, 2008.

Feenstra, R. C., Inklaar, R., and Timmer, M. P.: The Next Generation of the Penn World Table, Am. Econ. Rev., 105, 3150-3182, https://doi.org/10.1257/aer.20130954, 2015.

Fischer, E. M. and Knutti, R.: Anthropogenic contribution to global occurrence of heavy-precipitation and hightemperature extremes, Nat. Clim. Chang., 5, 560-564, https://doi.org/10.1038/nclimate2617, 2015.

Flato, G., Marotzke, J., Abiodun, B., Braconnot, P., Chou, S. C., Collins, W., Cox, P., Driouech, F., Emori, S., Eyring, V., Forest, C., Gleckler, P., Guilyardi, E., Jakob, C., Kattsov, V., and Reason, C., Rummukainen, M.: Evaluation of Climate Models, in Climate Change 2013: The Physical Science Basis. Contribution of Working Group I to the Fifth Assessment Report of the Intergovernmental Panel on Climate Change, 741-866, Cambridge University Press, Cambridge, United Kingdom and New York, NY, USA, 2013.

Food and Agriculture Organization of the United Nations: FAOSTAT, 2016.

Francis, J. A. and Vavrus, S. J.: Francis_2012_Evidence linking Arctic Amplification to Extreme Weather.pdf, Geophys. Res. Lett., 39, 1-6, https://doi.org/10.1029/2012GL051000, 2012.

Fricko, O., Havlik, P., Rogelj, J., Klimont, Z., Gusti, M., Johnson, N., Kolp, P., Strubegger, M., Valin, H., Amann, M., Ermolieva, T., Forsell, N., Herrero, M., Heyes, C., Kindermann, G., Krey, V., McCollum, D. L., Obersteiner, M., Pachauri, S., Rao, S., Schmid, E., Schoepp, W., and Riahi, K.: The marker quantification of the Shared Socioeconomic Pathway 2: A middle-of-the-road scenario for the 21st century, Glob. Environ. Chang., 42, 251-267, https://doi.org/10.1016/j.gloenvcha.2016.06.004, 2016.
Geiger, T.: Continuous national Gross Domestic Product (GDP) time series for 195 countries: past observations (1850-2005) harmonized with future projections according to the Shared Socioeconomic Pathways (2006-2100), Earth Syst. Sci. Data Discuss., https://doi.org/10.5194/essd-2017-80, in review, 2017.

Gosling, S. N., Zaherpour, J., Mount, N., Hattermann, F. F., Dankers, R., Arheimer, B., Breuer, L., Ding, J., Haddeland, I., Kumar, R., Kundu, D., Liu, J., Griensven, A. van, Veldkamp, T. I. E., Vetter, T., Wang, X., and Zhan, X.: A comparison of changes in river runoff from multiple global and catchment-scale hydrological models under global warming scenarios of $1^{\circ} \mathrm{C}, 2^{\circ} \mathrm{C}$ and $3^{\circ} \mathrm{C}$, Clim. Change, 141, 577-595, https://doi.org/10.1007/s10584-016-1761-7, 2016.

Hanewinkel, M., Cullmann, D. A., Schelhaas, M.-J., Nabuurs, G.J., and Zimmermann, N. E.: Climate change may cause severe loss in the economic value of European forest land, Nat. Clim. Chang., 3, 203-207, https://doi.org/10.1038/nclimate1687, 2012.

Harris, I., Jones, P. D., Osborn, T. J., and Lister, D. H.: Updated high-resolution grids of monthly climatic observations - the CRU TS3.10 Dataset, Int. J. Climatol., 34, 623-642, https://doi.org/10.1002/joc.3711, 2013.

Harrison, P. A., Robert, W. D., Holman, I. P., and Rounsevell, M. D. A.: Climate change impact modelling needs to include cross-sectoral interactions, Nat. Clim. Chang., 6, 885-890, https://doi.org/10.1038/nclimate3039, 2016.

Hempel, S., Frieler, K., Warszawski, L., Schewe, J., and Piontek, F.: A trend-preserving bias correction - the ISI-MIP approach, Earth Syst. Dynam., 4, 219-236, https://doi.org/10.5194/esd-4219-2013, 2013

Hirabayashi, Y., Mahendran, R., Koirala, S., Konoshima, L., Yamazaki, D., Watanabe, S., Kim, H., and Kanae, S.: Global flood risk under climate change, Nat. Clim. Chang., 3, 816-821, https://doi.org/10.1038/nclimate1911, 2013.

Hurtt, G., Chini, L., Sahajpal, R., Frolking, S., Calvin, K., Fujimori, S., K., G. K., Hasegawa, T., Havlik, P., Lawrence, D., Lawrence, P., Popp, A., Stehfest, E., van Vuuren, D., and Zhang, X.: Harmonization of global land-use change and management for the period 850-2100, in preparation, 2017.

Iizumi, T., Luo, J.-J., Challinor, A. J., Sakurai, G., Yokozawa, M., Sakuma, H., Brown, M. E., and Yamagata, T.: Impacts of El Niño Southern Oscillation on the global yields of major crops., Nat. Commun., 5, 3712, https://doi.org/10.1038/ncomms4712, 2014.

Internal Displacement Monitoring Centre and Norwegian Refugee Council: Global estimates 2015: People displaced by disasters, Geneva, available at: http://www.internal-displacement.org/ global-figures\#natural, 2015.

James, R., Otto, F., Parker, H., Boyd, E., Cornforth, R., Mitchell, D., and Allen, M.: Characterizing loss and damage from climate change, Nat. Clim. Chang., 4, 938-939, https://doi.org/10.1038/nclimate2411, 2014.

Jones, B. and O'Neill, B. C.: Spatially explicit global population scenarios consistent with the Shared Socioeconomic Pathways, Environ. Res. Lett., 11, 4003, https://doi.org/10.1088/17489326/11/8/084003, 2016.

Jones, P. W.: First- and Second-Order Conservative Remapping Schemes for Grids in Spherical Coordinates, Mon. Weather Rev., 127, 2204-2210, 1999. 
Klein Goldewijk, K.: A historical land use data set for the Holocene; HYDE 3.2, Data Arch. Networked Serv., https://doi.org/10.17026/dans-znk-cfy3, 2016.

Klein Goldewijk, K., Beusen, A., and Janssen, P.: Long term dynamic modeling of global population and built-up area in a spatially explicit way, HYDE 3.1, The Holocene, 20, 565-573, 2010.

Klein Goldewijk, K., Beusen, A., Van Drecht, G., and De Vos, M.: The HYDE 3.1 spatially explicit database of human-induced global land-use change over the past 12,000 years., Glob. Ecol. Biogeogr., 20, 73-86, 2011.

Kopp, R. E., Kemp, A. C., Bittermann, K., Horton, B. P., Donnelly, J. P., Gehrels, W. R., Hay, C. C., Mitrovica, J. X., Morrow, E. D., and Rahmstorf, S.: Temperature-driven global sea-level variability in the Common Era, P. Natl. Acad. Sci. USA, 113, E1434E1441, https://doi.org/10.1073/pnas.1517056113, 2016.

Lamarque, J.-F., Dentener, F., McConnell, J., Ro, C.-U., Shaw, M., Vet, R., Bergmann, D., Cameron-Smith, P., Dalsoren, S., Doherty, R., Faluvegi, G., Ghan, S. J., Josse, B., Lee, Y. H., MacKenzie, I. A., Plummer, D., Shindell, D. T., Skeie, R. B., Stevenson, D. S., Strode, S., Zeng, G., Curran, M., Dahl-Jensen, D., Das, S., Fritzsche, D., and Nolan, M.: Multi-model mean nitrogen and sulfur deposition from the Atmospheric Chemistry and Climate Model Intercomparison Project (ACCMIP): evaluation of historical and projected future changes, Atmos. Chem. Phys., 13, 7997-8018, https://doi.org/10.5194/acp-137997-2013, 2013a.

Lamarque, J.-F., Shindell, D. T., Josse, B., Young, P. J., Cionni, I., Eyring, V., Bergmann, D., Cameron-Smith, P., Collins, W. J., Doherty, R., Dalsoren, S., Faluvegi, G., Folberth, G., Ghan, S. J., Horowitz, L. W., Lee, Y. H., MacKenzie, I. A., Nagashima, T., Naik, V., Plummer, D., Righi, M., Rumbold, S. T., Schulz, M., Skeie, R. B., Stevenson, D. S., Strode, S., Sudo, K., Szopa, S., Voulgarakis, A., and Zeng, G.: The Atmospheric Chemistry and Climate Model Intercomparison Project (ACCMIP): overview and description of models, simulations and climate diagnostics, Geosci. Model Dev., 6, 179-206, https://doi.org/10.5194/gmd-6179-2013, 2013b.

Lange, S.: EartH2Observe, WFDEI and ERA-Interim data Merged and Bias-corrected for ISIMIP (EWEMBI), GFZ Data Serv., https://doi.org/10.5880/pik.2016.004, 2016.

Lange, S.: Bias correction of surface downwelling longwave and shortwave radiation for the EWEMBI dataset, Earth Syst. Dynam. Discuss., https://doi.org/10.5194/esd-2017-81, in review, 2017.

Lehner, B., Liermann, C. R., Revenga, C., Vörömsmarty, C., Fekete, B., Crouzet, P., Döll, P., Endejan, M., Frenken, K., Magome, J., Nilsson, C., Robertson, J. C., Rödel, R., Sindorf, N., and Wisser, D.: High-resolution mapping of the world's reservoirs and dams for sustainable river-flow management, Front. Ecol. Environ., 9, 494-502, https://doi.org/10.1890/100125, 2011.

Lotze-Campen, H., Müller, C., Bondeau, A., Rost, S., Popp, A., and Lucht, W.: Global food demand, productivity growth, and the scarcity of land and water resources: a spatially explicit mathematical programming approach, Agric. Econ., 39, 325-338, 2008.

Marzeion, B. and Levermann, A.: Loss of cultural world heritage and currently inhabited places to sea-level rise, Environ. Res. Lett., 9, 034001, https://doi.org/10.1088/1748-9326/9/3/034001, 2014.
Marzeion, B., Cogley, J. G., Richter, K., and Parkes, D.: Attribution of global glacier mass loss to anthropogenic and natural causes, Science, 345, 919-921, https://doi.org/10.1126/science.1254702, 2014.

McSweeney, C. F. and Jones, R. G.: How representative is the spread of climate projections from the 5 CMIP5 GCMs used in ISI-MIP, Clim. Serv., 1, 24-29, https://doi.org/10.1016/j.cliser.2016.02.001, 2016.

Mengel, M., Levermann, A., Frieler, K., Robinson, A., Marzeion, B., and Winkelmann, R.: Future sea level rise constrained by observations and long-term commitment, P. Natl. Acad. Sci. USA, 201500515, https://doi.org/10.1073/pnas.1500515113, 2016.

Monfreda, C., Ramankutty, N., and Foley, J. A.: Farming the planet: 2. Geographic distribution of crop areas, yields, physiological types, and net primary production in the year 2000, Glob. Biogeochem. Cycles, 22, GB1022, https://doi.org/10.1029/2007GB002947, 2008.

Müller Schmied, H., Adam, L., Eisner, S., Fink, G., Flörke, M., Kim, H., Oki, T., Portmann, F. T., Reinecke, R., Riedel, C., Song, Q., Zhang, J., and Döll, P.: Impact of climate forcing uncertainty and human water use on global and continental water balance components, Proc. IAHS, 374, 53-62, https://doi.org/10.5194/piahs-374-53-2016, 2016.

Munich Re, N.: Munich Re Natcatservice, Top. Geo 2014, 2015.

Murakami, D. and Yamagata, Y.: Estimation of gridded population and GDP scenarios with spatially explicit statistical downscaling, Environ. Res. Lett., in review, available at: https://arxiv.org/abs/ 1610.09041, 2017.

O’Neill, B. C., Kriegler, E., Ebi, K. L., Kemp-Benedict, E., Riahi, K., Rothman, D. S., van Ruijven, B. J., van Vuuren, D. P., Birkmann, J., Kok, K., Levy, M., and Solecki, W.: The roads ahead: Narratives for shared socioeconomic pathways describing world futures in the 21st century, Glob. Environ. Chang., 42, 169-180, https://doi.org/10.1016/j.gloenvcha.2015.01.004, 2014.

Piontek, F., Müller, C., Pugh, T. A. M., Clark, D. B., Deryng, D., Elliott, J., Colón González, F. de J., Flörke, M., Folberth, C., Franssen, W., Frieler, K., Friend, A. D., Gosling, S. N., Hemming, D., Khabarov, N., Kim, H., Lomas, M. R., Masaki, Y., Mengel, M., Morse, A., Neumann, K., Nishina, K., Ostberg, S., Pavlick, R., Ruane, A. C., Schewe, J., Schmid, E., Stacke, T., Tang, Q., Tessler, Z. D., Tompkins, A. M., Warszawski, L., Wisser, D., and Schellnhuber, H. J.: Multisectoral climate impact hotspots in a warming world., P. Natl. Acad. Sci. USA, 111, 3233-3238, https://doi.org/10.1073/pnas.1222471110, 2014.

Popp, A., Humpenöder, F., Weindl, I., Bodirsky, B. L., Bonsch, M., Lotze-Campen, H., Müller, C., Biewald, A., Rolinski, S., Stevanovic, M., and Dietrich, J. P.: Land-use protection for climate change mitigation, Nat. Clim. Chang., 4, 2-5, https://doi.org/10.1038/nclimate2444, 2014a.

Popp, A., Rose, S. K., Calvin, K., Vuuren, D. P. va., Dietrich, J. P., Wise, M., Stehfest, E., Humpenöder, F., Page, K., van Vliet, J., Bauer, N., Lotze-Campen, H., Klein, D., and Kriegler, E.: Land-use transition for bioenergy and climate stabilization: model comparison of drivers, impacts and interactions with other land use based mitigation options, Clim. Change, 123, 495-509, 2014 b.

Popp, A., Calvin, K., Fujimori, S., Havlik, P., Humpenöder, F., Stefest, E., Bodirsky, B., Dietrich, J., Doelmann, J., Gusti, M., Hasegawa, T., Kyle, P., Obersteiner, M., Tabeau, A., Takashi, K., 
Valin, H., Waldhoff, S., Weindl, I., Wise, M., Kriegler, E., LotzeCampen, H., Fricko, O., Ryahi, K., and Vurren, D. Van: Land use futures in the Shared Socio-Economic Pathways., Glob. Environ. Chang., 42, 331-345, 2017.

Riahi, K., van Vuuren, D. P., Kriegler, E., Edmonds, J., O’Neill, B., Fujimori, S., Bauer, N., Calvin, K., Dellink, R., Fricko, O., Lutz, W., Popp, A., Cuaresma, C. J., Samir, K., Leimback, M., Jiang, L., Kram, T., Rao, S., Emmerling, J., Ebi, K., Hasegawa, T., Havlik, P., Humpenöder, F., Da Silva, L. A., Smith, S., Stehfest, E., Bosetti, V., Eom, J., Gernaat, D., Masui, T., Rogelj, J., Strefler, J., Drouet, L., Krey, V., Luderer, G., Harmsen, M., Takahashi, K., Baumstark, L., Doelman, J., Kainuma, M., Klimont, Z., Marangoni, G., Lotze-Campen, H., Obersteiner, M., Tabeau, A., and Tavoni, M.: The shared socioeconomic pathways and their energy, land use, and greenhouse gas emissions implications: An overview, Glob. Environ. Chang., 42, 153-168, 2016.

Riahi, K., van Vuuren, D. P., Kriegler, E., Edmonds, J., O’Neill, B., Fujimori, S., Bauer, N., Calvin, K., Dellink, R., Fricko, O., Lutz, W., Popp, A., Crespo Cuaresma, J., Samir, K., Leimback, M., Jiang, L., Kram, T., Rao, S., Emmerling, J., Ebi, K., Hasegawa, T., Havlik, P., Humpenöder, F., Da Silva, L. A., Smith, S., Stehfest, E., Bosetti, V., Eom, J., Gernaat, D., Masui, T., Rogelj, J., Strefler, J., Drouet, L., Krey, V., Luderer, G., Harmsen, M., Takahashi, K., Baumstark, L., Doelman, J., Kainuma, M., Klimont, Z., Marangoni, G., Lotze-Campen, H., Obersteiner, M., Tabeau, A., and Tavoni, M.: The shared socioeconomic pathways and their energy, land use, and greenhouse gas emissions implications: An overview, Glob. Environ. Chang., 42, 153-168, 2017.

Rogelj, J., Luderer, G., Pietzcker, R. C., Kriegler, E., Schaeffer, M., Krey, V., and Riahi, K.: Energy system transformations for limiting end-of-century warming to below $1.5^{\circ} \mathrm{C}$, Nat. Clim. Chang., 5, 519-527, 2015.

Rosenzweig, C., Elliott, J., Deryng, D., Ruane, A. C., Müller, C., Arneth, A., Boote, K. J., Folberth, C., Glotter, M., Khabarov, N., Neumann, K., Piontek, F., Pugh, T. A. M., Schmid, E., Stehfest, E., Yang, H., and Jones, J. W.: Assessing agricultural risks of climate change in the 21 st century in a global gridded crop model intercomparison, P. Natl. Acad. Sci. USA, 14, 1-6, https://doi.org/10.1073/pnas.1222463110, 2014.

Roudier, P., Andersson, J. M., Donnelly, C., Feyen, L., Greuell, W., and Ludwig, F.: Projections of future floods and hydrological droughts in Europe under a $+2{ }^{\circ} \mathrm{C}$ global warming, Clim. Change, 135, 341-355, 2015.

Rust, H. W., Kruschke, T., Dobler, A., Fischer, M., and Ulbrich, U.: Discontinuous Daily Temperatures in the WATCH Forcing Datasets, J. Hydrometeorol., 16, 465-472, https://doi.org/10.1175/JHM-D-14-0123.1, 2015.

Samir, C. and Lutz, W.: The human core of the shared socioeconomic pathways: Population scenarios by age, sex and level of education for all countries to 2100, Glob. Environ. Chang., 42, 181-192, https://doi.org/10.1016/j.gloenvcha.2014.06.004, 2014.

Schellnhuber, H. J., Frieler, K., and Kabat, P.: The elephant, the blind, and the intersectoral intercomparison of climate impacts, P. Natl. Acad. Sci. USA, 111, 3225-3227, https://doi.org/10.1073/pnas.1321791111, 2013.

Schleussner, C.-F., Lissner, T. K., Fischer, E. M., Wohland, J., Perrette, M., Golly, A., Rogelj, J., Childers, K., Schewe, J., Frieler, K., Mengel, M., Hare, W., and Schaeffer, M.: Differen- tial climate impacts for policy-relevant limits to global warming: the case of $1.5^{\circ} \mathrm{C}$ and $2^{\circ} \mathrm{C}$, Earth Syst. Dynam., 7, 327-351, https://doi.org/10.5194/esd-7-327-2016, 2016.

Sheffield, J., Goteti, G., and Wood, E. F.: Development of a 50-year high-resolution global dataset of meteorological forcings for land surface modeling., J. Climate, 19, 3088-3111, https://doi.org/10.1175/JCLI3790.1, 2006.

Sippel, S., Otto, F. E. L., Forkel, M., Allen, M. R., Guillod, B. P., Heimann, M., Reichstein, M., Seneviratne, S. I., Thonicke, K., and Mahecha, M. D.: A novel bias correction methodology for climate impact simulations, Earth Syst. Dynam., 7, 71-88, https://doi.org/10.5194/esd-7-71-2016, 2016.

Sperber, K. R., Annamalai, H., Kang, I.-S., Kitoh, A., Moise, A., Turner, A., Wang, B., and Zhou, T.: The Asian summer monsoon: an intercomparison of CMIP5 vs. CMIP3 simulations of the late 20th century, Clim. Dynam., 41, 2711-2744, https://doi.org/10.1007/s00382-012-1607-6, 2013.

Stackhouse Jr., P. W., Gupta, S. K., Cox, S. J., Mikovitz, C., Zhang, T., and Hinkelman, L. M.: The ASA/GEWEX surface radiation budget release 3.0: 24.5-year dataset, Gewex news, 21, 10-12, 2011.

Stevanović, M., Popp, A., Lotze-Campen, H., Dietrich, J. P., Müller, C., Bonsch, M., Schmitz, C., Bodirsky, B., Humpenöder, F., and Weindl, I.: High-end climate change impacts on agricultural welfare, Sci. Adv., 2, e1501452 https://doi.org/10.1126/sciadv.1501452, 2016.

Taylor, K. E., Stouffer, R. J., and Meehl, G. A.: An Overview of CMIP5 and the Experiment Design, B. Am. Meteorol. Soc., 93, 485-498, 2012.

UNFCCC: Adoption of the Paris Agreement, Decision 1/CP.21 of FCCC/CP/2015/10/Add.1, available at: http://unfccc.int/resource/docs/2015/cop21/eng/10a01.pdf (last access: July 2016), 2015.

Wada, Y., van Beek, L. P. H., Sperna Weiland, F. C., Chao, B. F., Wu, Y.-H., and Bierkens, M. F. P.: Past and future contribution of global groundwater depletion to sea-level rise, Geophys. Res. Lett., 39, 1-6, https://doi.org/10.1029/2012GL051230, 2012.

Wada, Y., Flörke, M., Hanasaki, N., Eisner, S., Fischer, G., Tramberend, S., Satoh, Y., van Vliet, M. T. H., Yillia, P., Ringler, C., Burek, P., and Wiberg, D.: Modeling global water use for the 21st century: the Water Futures and Solutions (WFaS) initiative and its approaches, Geosci. Model Dev., 9, 175-222, https://doi.org/10.5194/gmd-9-175-2016, 2016.

Ward, P. J., Jongman, B., Kummu, M., Dettinger, M. D., Sperna Weiland, F. C., and Winsemius, H. C.: Strong influence of El Nino Southern Oscillation on flood risk around the world, P. Natl. Acad. Sci. USA, 111, 15659-15664, https://doi.org/10.1073/pnas.1409822111, 2014.

Warren, R.: The role of interactions in a world implementing adaptation and mitigation solutions to climate change., Philos. Trans. A. Math. Phys. Eng. Sci., 369, 217-241, https://doi.org/10.1098/rsta.2010.0271, 2011.

Warszawski, L., Frieler, K., Huber, V., Piontek, F., Serdeczny, O., and Schewe, J.: The Inter-Sectoral Impact Model Intercomparison Project (ISI-MIP): project framework, P. Natl. Acad. Sci. USA, 111, 3228-3232, https://doi.org/10.1073/pnas.1312330110, 2014.

Watanabe, M., Suzuki, T., O'ishi, R., Komuro, Y., Watanabe, S., Emori, S., Takemura, T., Chikira, M., Ogura, T., 
Sekiguchi, M., Takata, K., Yamazaki, D., Yokohata, T., Nozawa, T., Hasumi, H., Tatebe, H., and Kimoto, M.: Improved Climate Simulation by MIROC5: Mean States, Variability, and Climate Sensitivity, J. Climate, 23, 6312-6335, https://doi.org/10.1175/2010JCLI3679.1, 2010.

Watanabe, S., Hajima, T., Sudo, K., Nagashima, T., Takemura, T., Okajima, H., Nozawa, T., Kawase, H., Abe, M., Yokohata, T., Ise, T., Sato, H., Kato, E., Takata, K., Emori, S., and Kawamiya, M.: MIROC-ESM 2010: model description and basic results of CMIP5-20c3m experiments, Geosci. Model Dev., 4, 845-872, https://doi.org/10.5194/gmd-4-845-2011, 2011.

Weedon, G. P., Gomes, S., Viterbo, P., Österle, H., Adam, J. C., Bellouin, N., Boucher, O., and Best, M.: The WATCH forcing data 1958-2001: A meteorological forcing dataset for land surface and hydrological models, in: Technical Report no 22., available at: http://www.eu-watch.org/publications/technical-reports (last access: July 2016), 2010.

Weedon, G. P., Gomes, S., Viterbo, P., Shuttleworth, W. J., Blyth, E., Österle, H., Adam, J. C., Bellouin, N., Boucher, O., and Best, M.: Creation of the WATCH Forcing Data and Its Use to Assess Global and Regional Reference Crop Evaporation over Land during the Twentieth Century, J. Hydrometeorol., 12, 823-848, https://doi.org/10.1175/2011JHM1369.1, 2011.
Weedon, G. P., Balsamo, G., Bellouin, N., Gomes, S., Best, M. J., and Viterbo, P.: The WFDEI meteorological forcing data set: WATCH Forcing Data methodology applied to ERAInterim reanalysis data, Water Resour. Res., 50, 7505-7514, https://doi.org/10.1002/2014WR015638, 2014.

Wilks, D. S.: Statistical Methods in the Atmospheric Sciences, Academic Press, San Diego, CA, 1995.

Winkelmann, R. and Levermann, A.: Linear response functions to project contributions to future sea level, Clim. Dynam., 40, 2579-2588, https://doi.org/10.1007/s00382-012-1471-4, 2013.

Wu, P., Wood, R., Ridley, J., and Lowe, J.: Temporary acceleration of the hydrological cycle in response to a $\mathrm{CO}_{2}$ rampdown, Geophys. Res. Lett., 37, L12705, https://doi.org/10.1029/2010GL043730, 2010.

Zappa, G., Shaffrey, L. C., and Hodges, K. I.: The Ability of CMIP5 Models to Simulate North Atlantic Extratropical Cyclones, J. Climate, 26, 5379-5396, https://doi.org/10.1175/JCLID-12-00501.1, 2013. 